\title{
Modern methods for studying polymer complexes in aqueous and organic solutions
}

Article

Accepted Version

Khutoryanskiy, V. V., Smyslov, R. Y. and Yakimansky, A. V. (2018) Modern methods for studying polymer complexes in aqueous and organic solutions. Polymer Science Series A, 60 (5). pp. 553-576. ISSN 1555-6107 doi:

https://doi.org/10.1134/S0965545X18050085 Available at https://centaur.reading.ac.uk/79019/

It is advisable to refer to the publisher's version if you intend to cite from the work. See Guidance on citing.

Published version at: https://link.springer.com/article/10.1134/S0965545X18050085

To link to this article DOI: http://dx.doi.org/10.1134/S0965545X18050085

Publisher: Springer

All outputs in CentAUR are protected by Intellectual Property Rights law, including copyright law. Copyright and IPR is retained by the creators or other copyright holders. Terms and conditions for use of this material are defined in the End User Agreement.

www.reading.ac.uk/centaur 
Central Archive at the University of Reading

Reading's research outputs online 
Хуторянский Виталий Викторович $+44(0) 1183786119$

УДК

Современные методы исследования полимерных комплексов

в водных и органических растворах

(обзор)

(c) 2017 г. Хуторянский В.В., ${ }^{1}$ Смыслов Р.Ю., ${ }^{2,3}$ Якиманский А.В., ${ }^{2,4}$

${ }^{1}$ Reading School of Pharmacy, University of Reading, Whiteknights, PO Box

224, Reading RG6 6AD, United Kingdom

2 ФГБУН Институт высокомолекулярных соединений РАН, Санкт-

Петербург, Большой пр. 31, 199004 Санкт-Петербург, Россия

3 Национальный исследовательский центр «Курчатовский институт», Петербургский институт ядерной физики, Гатчина, Орлова роща, Россия

${ }^{4}$ Институт химии СПбГУ, Петродворец, Университетский пр. 26, 198504 Санкт-Петербург, Россия

Поступила в редакцию

Принята в печать 


\begin{abstract}
Аннотация
В обзоре рассмотрены некоторые современные методы физикохимического анализа, которые применяются для исследования процессов комплексообразования полимеров в растворах. Одни из них - динамическое светорассеяние, анализ траекторий наночастиц, просвечивающая электронная микроскопия, криопросвечивающая электронная микроскопия, атомно-силовая микроскопия, малоугловое рассеяние нейтронов, аналитическая скоростная седиментация и люминесцентные методы - позволяют исследовать структуру образующихся комплексов; другие - изотермического калориметрического титрования и метод поверхностного плазмонного резонанса - позволяют оценить интенсивность специфических взаимодействий между компонентами комплекса.
\end{abstract}

Ключевые слова: наночастицы, интерполимерные комплексы, поликомплексы, полиэлектролиты, физико-химические методы

E-mail: v.khutoryanskiy@reading.ac.uk (Хуторянский Виталий Викторович) 


\section{1. Введение}

Функциональные полимеры обладают уникальной способностью к процессам самосборки и взаимодействию с большими и малыми молекулами в водных растворах, которые приводят к образованию полимерных комплексов, ассоциатов, наноструктур, агрегатов, гелей, а также моно- и мультислоев. Движущей силой в таких случаях выступают различные специфические взаимодействия: силы электростатического притяжения, водородные и координационные связи, и эффекты гидрофобной природы. $\mathrm{B}$ зависимости от вида специфических взаимодействий, а также от природы молекул, образующих комплексы, различают несколько классов полимерных систем: интерполиэлектролитные комплексы (ИПЭК), интерполимерные комплексы с водородными связями (ИПК), комплексы полимеров с поверхностно-активными веществами (ПАВ), металл-полимерные комплексы (МПК) на основе $d$ - и $f$-элементов, комплексы полимеров с лекарственными веществами (КПЛ) и комплексы анионных полимеров с некоторыми катионами s-элементов.

A. Интерполиэлектролитные комплексы; возникают при взаимодействии противоположно заряженных полимеров [1-6]. В результате реакции между функциональными группами полиэлектролитов образуются солевые связи, возникновение которых сопровождается выделением низкомолекулярных ионов в раствор. Такие комплексы могут 
быть как стехиометрического, так и нестехиометрического состава. Для стехиометрического комплекса мольное соотношение между противоположно заряженными группами обычно составляет 1:1 и, как правило, подобные поликомплексы формируются в виде коллоидных дисперсий. Формирование ИПЭК зависит от структуры полиэлектролитов (длина и гибкость цепи, природа и распределение заряженных групп, гидрофобность макромолекул и т.д.) и условий комплексообразования (ионная сила раствора, $\mathrm{pH}$, качество растворителя и температура). Нестехиометрические ИПЭК в отличие от стехиометрических растворяются в воде [3] за счет не связанных межмакромолекулярным взаимодействием фрагментов. Возможности использования интерполиэлектролитных комплексов ДНК с линейными поликатионами для применения в медицине как средства доставки генетического материала в клетку подробно рассмотрены в обзоре [7]. ИПЭК также находят применение в других областях фармацевтики, например, как вспомогательные вещества при создании твердых лекарственных форм [8, 9] и капсул $[10,11]$.

Б. Интерполимерные комплексы с водородными связями (ИПК); образуются в результате объединения макромолекул, взаимодействующих между собой за счёт образования множественных межмакромолекулярных контактов, формирование которых зависит от химической природы мономерных звеньев, участвующих во взаимодействии, от состава, т. е. 
количества тех или иных участков макромолекул, включённых в ИПК, и от устойчивости контактов, стабилизирующих поликомплекс. ИПК в настоящее время рассматривают как полимерные вещества, обладающие свойствами, отличными от свойств исходных компонентов. Такие системы образуются при взаимодействии поликарбоновых кислот с неионными протоноакцепторными полимерами и стабилизированы кооперативной системой водородных связей [1, 12-14]. Например, ИПК, образованные полиакриловой кислотой (ПАК) в смесях с полиэтиленоксидом (ПЭО), поливинилпирролидоном (ПВП), полиакриламидом (ПААм), поливиниловым спиртом (ПВС), простыми эфирами целлюлозы и другими неионными полимерами. Характерной особенностью ИПК является их рНзависимая стабильность в водных растворах. Как правило, ИПК образуются в кислых средах при $\mathrm{pH}$ ниже определенных критических значений ( $\left.\mathrm{pH}_{\text {крит }}\right)$.

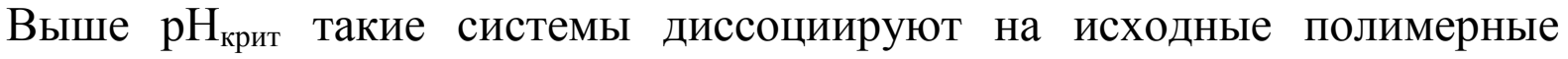
компоненты. ИПК находят применение в технологиях производства лекарственных форм в качестве мукоадгезивных пленок, таблеток и гелей [15].

В. Стереополикомплексы (СПК) образуются в результате вандерваальсовых взаимодействий стерически комплементарных участков макромолекул в некоторых органических растворителях. Примерами таких комплексов являются СПК, образованные при смешении растворов изо- и синдиотактического (синдио-) полиметилметакрилатов (ПММА) [16-18], а 
также стереотактических полилактонов [19]. Такие комплексы могут найти свое применение при создании композитов с микрофазным разделением для материалов с эффектом памяти формы [20].

В. Комплексы полимеров с поверхностно-активными веществами (ПАВ). Такие поликомплексы могут быть образованы либо при взаимодействии полиэлектролитов с противоположно заряженными ПАВ, либо посредством гидрофобных эффектов для однозарядных или неионных систем [21]. Существенную роль в структурообразовании в таких системах играют концентрационные эффекты, например, наличие критической концентрации мицеллообразования ПАВ. Комплексы полимеров с ПАВ обладают интересными поверхностно-активными свойствами и находят применение в тех областях, где требуется увеличение поверхностной энергии, например, при создании моющих средств, флотационных реагентов, стабилизаторов эмульсий и флокулянтов [22]. Возможны также комплексы, образованные мицеллами ПАВ и липосомами с противоположно заряженными полимерами; такие системы могут найти применение как носители лекарственных препаратов [23].

Г. Металл-полимерные комплексы (МПК); представляют координационные комплексы полимеров с ионами переходных металлов. Эти комплексы могут быть образованы при взаимодействии катионных полимеров, например, полиэтиленимина или поли-4-винилпиридина, с ионами $\mathrm{Cu}^{2+}, \mathrm{Co}^{2+}, \mathrm{Ni}^{2+}$ и другими $[24,25]$. Возможны также комплексы 
катионных полимеров с некоторыми низкомолекулярными координационными соединениями, например, ионами $\left[\mathrm{Fe}(\mathrm{CN})_{6}\right]^{3+}[26]$. Как правило взаимодействия в таких системах сопровождаются изменением конформации макромолекул, при этом возможно формирование как комплексов внутримолекулярной, так и межмакромолекулярной природы. Интерес к таким системам обусловлен их уникальными каталитическими свойствами [24, 25, 27], а также возможностью использования реакций комплексообразования для извлечения ионов тяжелых металлов, например, для очистки сточных вод [28]. В настоящее время разрабатываются и используются новые каталитические системы. Так в работе [29] использовали карборановый комплекс рутения вместе с изопропиламином для проведения контролируемой свободно-радикальной полимеризации изоборнил акрилата, изоборнил метакрилата (ИБМА) и трет-бутил метакрилата (ТБМА) посредством механизма радикальной полимеризации с переносом атома (ATRP). Авторам удалось успешно синтезировать диблок- и триблок-сополимеры на основе фрагментов метилметакрилата (ММА), ИБМА и ТБМА, используя данную каталитическую систему. Для визуализации процессов в биологических системах находят применение МПК с f-элементами, например, с $\mathrm{Tb}^{3+}, \mathrm{Eu}^{3+}$ и $\mathrm{Sm}^{3+}$ благодаря уникальному спектру люминесценции ионов (III) лантанидов [30-35].

Д. Комплексы полимеров с лекарственными вещеествами (КПЛ). Комплексообразование в таких системах может осуществляться 
посредством различных взаимодействий (сил электростатической природы, водородных связей и гидрофобных эффектов), а также их комбинации. Например, смешение полиакриловой кислоты с гидрохлоридом лидокаина [36] или стрептомицина сульфатом [37] в водных растворах приводит к образованию коллоидных поликомплексов, склонных к постепенному осаждению. В некоторых случаях такие взаимодействия могут быть использованы при создании полимерных лекарственных систем с контролируемым и медленным высвобождением активного начала [38]. Однако, процессы комплексообразования полимеров с лекарственными веществами могут также быть и нежелательны, из-за возможного снижения фармакологической активности препаратов.

Е. Комплексы анионных полимеров с катионами щелочноземельных металлов (например, $\mathrm{Ca}^{2+}$ ). Классическим примером взаимодействия в такой системе является процесс образования физического геля при смешении водного раствора альгината натрия с водорастворимыми солями кальция [39]. В настоящее время такие комплексы находят широкое применение в пищевых технологиях, например, для инкапсулирования живых бактерий-пробиотиков [40].

Существуют также более сложные системы, например, тройные комплексы полимер - ионы металла - полимер или полимер - наночастица металла - полимер [41], либо полимер - циклодекстрин - полимер [42].

Многолетние исследования процессов комплексообразования в 
полимерных системах заложили фундаментальные основы для понимания структуры комплексов, их физико-химических свойств, а также применения в различных областях. Эти основы были подробно рассмотрены в многочисленных ранних обзорах и монографиях [1-3, 12, 43, 44]. Цель данного обзора - показать новые достижения с использованием классических методов анализа структуры ИПК и процессов комплексообразования в водных растворах (светорассеяние, турбидиметрия, люминесценция), рассмотреть устоявшиеся (просвечивающая электронная микроскопия, атомносиловая микроскопия) и появившиеся недавно методы исследования ИПК (анализ траекторий наночастиц, просвечивающая электронная микроскопия, изотермическое калориметрическое титрование, поверхностный плазмонный резонанс), их возможности для исследования известных и новых полимерных систем. Мы также стремились показать новые технические возможности классических методов, например, малоуглового рассеяния нейтронов и рентгеновского излучения, поскольку в настоящее время запускаются мощные источники нейтронов и синхротронного излучения нового поколения.

\section{2. Методы исследования структуры комплексов в растворах}

В ранних работах по комплексообразованию полимеров в растворах широко использовались методы потенциометрии, кондуктометрии, турбидиметрии и вискозиметрии. Эти методы, как правило, позволяли лишь установить сам факт взаимодействия, а также произвести некоторую 
оценку стабильности и компактности образующихся комплексов $[3,13,45]$. С развитием нанотехнологий в настоящее время становятся доступными множество новых методов физико-химического анализа, способных дать качественную и количественную информацию о размерах, форме и структуре полимерных комплексов.

В данном разделе будут кратко рассмотрены статическое и динамическое светорассеяние, анализ траекторий наночастиц, просвечивающая электронная микроскопия, атомносиловая микроскопия, малоугловое рассеяние нейтронов, а также методы абсорбционной и люминесцентной спектроскопии.

\section{1. Статическое и динамическое рассеяние света}

Методы статического и динамического светорассеяния могут использоваться для исследования растворов полимеров, мицеллярных структур, агрегатов, наночастиц, эмульсий и других коллоидов. Они также нашли широкое применение в исследованиях структуры полимерных комплексов, образующихся в растворах.

Статическое рассеяние света (СРС) основано на измерении интенсивности рассеянного света для получения информации о молекулярной массе макромолекул в разбавленных растворах. Являясь абсолютным методом определения молекулярной массы и размеров макромолекул в растворе, СРС не требует предварительной калибровки и использования эталонов. Метод позволяет определять термодинамические 
параметры взаимодействия полимер-растворитель через второй вириальный коэффициент, $A_{2}$, и дает информацию о полидисперсности полимера. Измерение интенсивности рассеянного света при разных углах позволяет рассчитывать среднеквадратический радиус инерции, $\left\langle R_{g}^{2}\right\rangle^{1 / 2}$, для нескольких образцов полимеров различной концентрации [46].

Размер достаточно большой полимерной частицы в растворе порядка 100 нм. Он попадает в диапазон от $\lambda_{0} / 20$ до $\lambda_{0}-$ длины волны падающего света, используемой в методе СРС, - когда справедливо уравнение ДебаяЗимма [47]:

$$
\frac{K \cdot c}{R_{\theta}}=\frac{1}{M_{w}}\left(1+\frac{q^{2}}{3}\left\langle R_{g}^{2}\right\rangle\right)+2 A_{2} C
$$

где $K$ - оптическая постоянная раствора, равная $\frac{4 \pi^{2} n_{0}^{2}(d n / d c)^{2}}{\lambda_{0}^{4} N_{A}}$ для вертикально поляризованного падающего света;

$n_{0}$ - показатель преломления растворителя;

$d n / d c-$ инкремент показателя преломления;

c- концентрация полимера, г/мл;

$N_{A}$ - число Авогадро;

$R_{\theta}-$ рэлеевское отношение (коэффициент рассеяния) или приведенная интенсивность избыточного рассеяния;

$q=\frac{4 \pi n_{0}}{\lambda_{0}} \sin \frac{\theta}{2}-$ модуль волнового вектора рассеяния;

$\theta-$ угол рассеяния; 
$M_{\mathrm{w}}$ - средневзвешенная молекулярная масса, г/моль.

Соотношение (1) справедливо для растворов полимеров, когда средний показатель преломления частицы $n^{\prime}$ близок к $n_{0}$ [47]. Современные схемы измерения CPC, например, реализованные в фотометре DAWN® HELEOS® (WYATT Technology, Калифорния) [48], предполагают использование набора детекторов с фиксированными углами наблюдения, что позволяет проводить одновременно измерения при различных углах. В таком случае полное время измерения меньше, чем, если бы использовали механически управляемую установку, позволяющую проводить измерения последовательно для каждого отдельного угла. Следует отметить, что установки с набором детекторов, позволяющих проводить измерения при разных углах, доступны также и у других производителей, например, компании ALV GmbH.

В пределе низких концентраций полимера, например, для жидкостной хроматографии, в уравнении Дебая-Зимма (1) можно выделить функцию форм-фактора, $P_{\theta}$, связывающую угловую зависимость интенсивности рассеянного света с размером и внутренней структурой макромолекул - пространственным распределением сегментов внутри макромолекулы:

$$
1 / P_{\theta} \cong 1+\frac{q^{2}}{3}\left\langle R_{g}^{2}\right\rangle .
$$


Видно, что приближение (2) связано с уравнением Дебая-Зимма (1), поскольку $R_{\theta}=K c M_{w} P_{\theta}$ [47]. В малых углах изменение дебаевской функции $1 / P_{\theta}$ пропорционально распределению массы внутри одной частицы, т.е. полимерной цепи, что отражается в измеряемом среднеквадратичном радиусе инерции .

Зависимость $K c / R_{\theta}$ от $\sin ^{2}(\theta / 2)$ или $q$ в области низких концентраций, характерных для хроматографических экспериментов, представляет собой кривую, чье пересечение с осью ординат, когда $q=0$, дает $M_{w}$, а начальный наклон пропорционален величине $\left\langle R_{g}^{2}\right\rangle$ [49]. При варьировании концентрации $c$ в малых углах, когда $q$ близко к 0 , начальный наклон зависимости $K c / R_{\theta}$ от позволяет рассчитать величину второго вириального коэффициента $A_{2}$. Метод двойной экстраполяции с использованием уравнения Дебая-Зимма (1) независим от каких-либо модельных представлений о структуре частицы, т.е. не требует знания о молекулярной конформации или степени ветвления макромолекул [47].

В отличие от статического принцип действия динамического рассеяния света (ДРС) заключается в измерении функции интенсивности света, рассеянного частицами, присутствующими в дисперсии, во времени. При освещении коллоидной дисперсии лазерным лучом, происходит его рассеяние во всех направлениях, поскольку частицы претерпевают хаотическое броуновское движение. Флуктуации рассеянного света 
измеряются при постоянном угле при помощи скоростного детектора фотонов, соединенного с цифровым коррелятором.

Измеряемую автокорреляционную фунцию флуктуаций интенсивности рассеянного света во времени для систем с молекулярно-

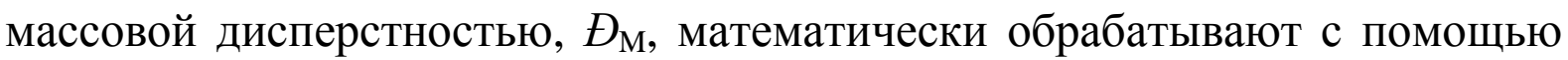
соотношения Зигерта в интегральном виде [50]:

$$
g_{2}(\tau)=1+a\left[\int_{D_{\min }}^{D_{\max }} z(D) \exp \left(-q^{2} D \tau\right)\right]^{2}
$$

$a-$ числовой параметр;

$\tau$-характерное время релаксации флуктуаций концентрации рассеивающих частиц.

$z(D)$ - функция распределения рассеивающих частиц в зависимости от коэффициента поступательной диффузии $D$;

$q=\frac{4 \pi n}{\lambda_{0}} \sin \frac{\theta}{2}-$ модуль волнового вектора рассеянного света в среде (растворе) с показателем преломления $n$, и углом рассеяния $\theta$.

Интеграл в выражении для функции $g_{2}(\tau)$ представляет собой нормированную временную автокорреляционную функцию $g_{1}(\tau)$ для флуктуаций вектора рассеянного электрического поля, $E(t)$ [51]. Множитель $a$ зависит от геометрии измеряемой системы. Для систем, обладающих единственным размером, т. е., при отсутствии дисперсии, $g_{1}(\tau)$ - одноэкспоненциальная функция $\exp \left(-q^{2} D \tau\right)$. Для систем, обладающих молекулярно-массовой дисперстностью $\bigoplus_{\mathrm{M}}$, функция $g_{1}(\tau)$ не 
является больше одноэкспоненциальной и должна быть заменена интегральной суммой, нормированной по распределению затухающих скоростей $z(D)$, как дано в уравнении 3 [51].

Анализ функции автокорреляции интенсивности от времени дает коэффициент поступательной диффузии частиц, $D$, который может использоваться для расчета их гидродинамического радиуса, $R_{h}$, по уравнению Эйнштейна-Стокса [52]:

$$
D=\frac{k_{\mathrm{B}} T}{6 \pi \eta R_{h}}
$$

где $k_{\mathrm{B}}$ - постоянная Больцмана, $T$ - абсолютная температура и $\eta-$ динамическая вязкость растворителя.

Метод ДРС позволяет исследовать размеры и распределение по размерам для малых частиц, диспергированных в жидкости (как правило, для частиц с диаметром менее нескольких микрометров). Ограничением метода является высокая концентрация частиц в дисперсии, приводящая к эффекту многократного рассеяния из-за последовательного взаимодействия луча с несколькими частицами. В данном случае результаты измерений не будут достоверны, поэтому рекомендуется работать с разбавленными дисперсиями частиц. Однако, в случае сильно рассеивающих свет систем, когда использование метода динамического светорассеяния в традиционном варианте не дает достоверную информацию из-за эффекта многократного рассеяния, возможно использование динамического 
светорассеяния с трёхмерной кросс-корреляцией [53]. Вторым существенным ограничением являются сложности при измерениях полидисперсных систем. В таких системах луч будет эффективнее рассеиваться более крупными частицами и малые объекты не всегда могут регистрироваться. При этом, измерения могут проводиться только для частиц, которые не подвергаются быстрому осаждению.

Литманович с соавторами [54] определили молекулярную массу комплексов, образованных полиакриловой кислотой (ПАК, 161 кДа) и полидиаллилдиметиламмоний-хлоридом (ПДАДМАХ, 415 кДа) в 0.1 М растворах $\mathrm{HCl}$ при $40{ }^{\circ} \mathrm{C}$ (соотношение ПДАДМАХ/ПАК в смеси $c a .0 .18$ ). Установлено формирование ассоциатов с гидродинамическим радиусом 97 нм и молекулярной массой 1500 кДа, в которых на одну макромолекулу ПДАДМАХ приходится 6-7 макромолекул ПАК. Отношение гидродинамического радиуса к радиусу инерции $\left(R_{\mathrm{h}} / R_{\mathrm{g}}\right)$ для таких ассоциатов составило 1.2 , что близко к величине, соответствующей плотным сферическим частицам [55].

В работе [56] были исследованы интерполимерные комплексы (ИПК) полиакриловой кислоты (ПАК) с поливинилпирролидоном (ПВП), а также сополимерами винилпирролидона с винилпропиловым эфиром (ВПЭ) в водных растворах. На рис. 1 приведены кривые распределения ИПК по размерам, полученные методом ДРС. Данные эксперименты показали присутствие в системе частиц нескольких популяций как результат 
формирования ИПК. Например, смешение ПАК с ПВП может приводить к образованию двух категорий частиц поликомплексов ПАК-ПВП, размеры которых $23 \pm 1$ и $129 \pm 2$ нм. В серии повторных экспериментов обнаружено, что частицы $23 \pm 1$ нм наблюдаются не всегда. Это позволяет предположить, что формирование частиц $23 \pm 1$ нм имеет место на начальных этапах комплексообразования. Эти “первичные” частицы постепенно агрегируют и ведут к образованию более крупных ИПК с размером $129 \pm 2$ нм. Таким образом, система ПАК-ПВП гетерогенна по размерам частиц; причем размеры ИПК изменяются во времени, «первичные» комплексы агрегируют и образуют крупные ИПК.

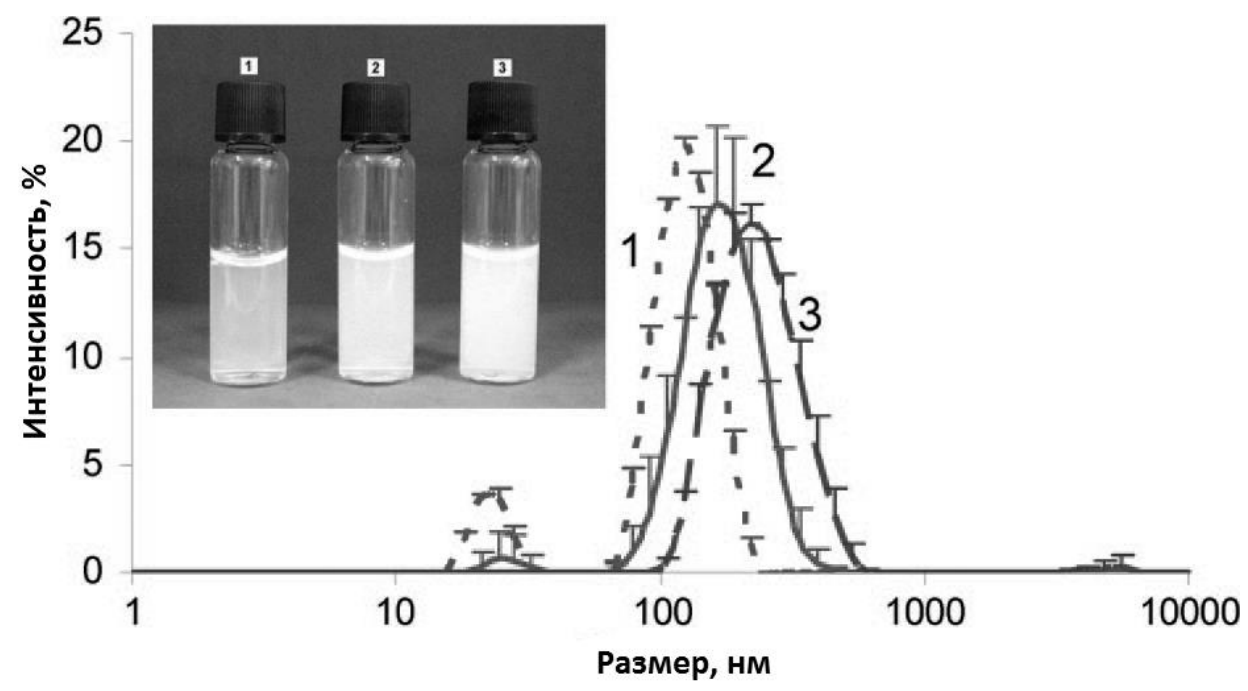

Рис. 1. Кривые распределения по размерам ИПК, полученных смешением водных растворов ПАК с ПВП при эквимольных соотношениях мономерных звеньев (1) и ПАК с сополимерами ВП, содержащими 25.5 мол. \% (2) и 29.2 мол. \% (3) ВПЭ, при рН 3.0. Концентрации полимеров 0.01 моль/л. Вставка - фотографии соответствующих дисперсий поликомплексов. Из работы [56] с разрешения издательства American Chemical Society. 
ИПК, образованные более гидрофобными сополимерами ВП с ВПЭ, дают более крупные частицы, размер которых зависит от содержания ВПЭ в системе. Длительное хранение таких растворов также приводит к росту агрегатов, размеры которых превышают 1 мкм.

Формирование нескольких групп частиц было обнаружено также Литманович с соавторами [54] при исследовании влияния температуры раствора на структуру полиэлектролитных ассоциатов, образованных в смесях ПАК с ПДАДМАХ. Авторами было установлено, что при высокой температуре $\left(70{ }^{\circ} \mathrm{C}\right)$ в водных смесях ПАК - ПДАДМАХ присутствуют частицы, гидродинамический радиус которых составляет 28 нм, что близко к размерам клубков катионного полимера (27 нм). По мере снижения температуры наблюдается появление частиц большего размера, при этом система характеризуется бимодальным распределением по размерам, т.е. формируются как незакомплексованные клубки полимеров (27 нм), так и более крупные ассоциаты. При $40{ }^{\circ} \mathrm{C}$ в растворе присутствует только один вид частиц с гидродинамическим радиусом 97 нм. Дальнейшее снижение температуры сопровождается фазовым расслоением системы. Авторы отмечают [54], что изменения в структуре ассоциатов являются полностью обратимыми и повышение температуры в дисперсии, содержащей более крупные агрегаты, приводит к уменьшению размеров частиц.

Пергушовым с соавторами исследованы водорастворимые комплексы звездообразной ПАК с кватернизированным поли(4-винилпирридином) 
[57]. Методами СРС и ДРС, а также турбидиметрии показано образование двух сосуществующих популяций комплексных частиц, значительно различающихся по своим размерам. Авторы полагают, что частицы меньшего размера, составляющие основную фракцию, представляют собой водорастворимые ИПК, в то время как частицы большего размера являются комплексными агрегатами с мольным отношением полимеров, близким к $1: 1$.

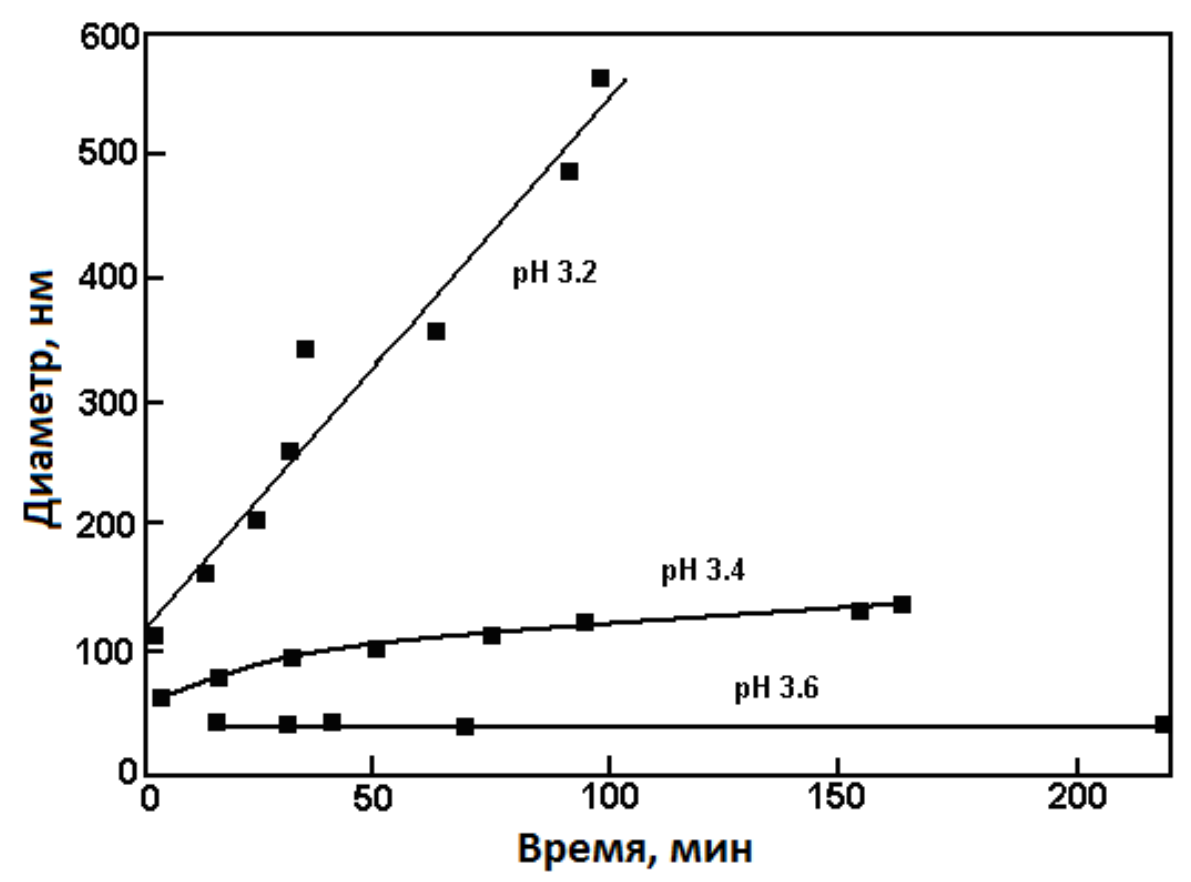

Рис. 2. Агрегация частиц ИПК, образованных ПАК и ПВП при различных $\mathrm{pH}$. ИПК были приготовлены путем смешения эквимольных соотношений мономерных звеньев при $5 \times 10^{-3}$ осн.-моль/л. Диаметр связан с гидродинамическим радиусом рассеивающих частиц как $d=2 R_{\mathrm{h}}$. Из работы [58] $\mathrm{c}$ разрешения издательства Elsevier.

Динамическое светорассеяние может применяться не только для определения размеров частиц поликомплексов, но и для исследования кинетики их агрегации. Например, в работе [58] была исследована 
агрегация поликомплексов, образованных смешением водных растворов ПАК с ПВП при различных рН. Установлено, что наиболее интенсивная агрегация наблюдается при рН 3.2, когда диаметр частиц увеличивается от 100 до 550 нм в течение 100 мин. (рис. 2). При более высоких значениях рН (3.4 и 3.6) агрегация была менее интенсивна и приводила к образованию частиц меньшего размера (50-100 нм при рН 3.4 и 40 нм при рН 3.6).

Характеристики системы, на которые следует обращать внимание в эксперименте: гетерогенность, время, этапы, которые проходит система при формировании ИПК, $\mathrm{pH}$ раствора и температурный режим.

\section{2. Анализ траекторий наночастиц}

Анализ траекторий наночастиц (АТН) - по англ. nanoparticle tracking analysis (NTA) позволяет исследовать броуновское движение коллоидных частиц, диспергированных в жидкости. Метод АТН разработан компанией NanoSight Ltd [59] для измерения размеров наночастиц посредством компьютерного анализа траекторий их движения. Такой анализ становится возможен при использовании ультрамикроскопа и специальной видеокамеры, позволяющей регистрировать свет, рассеянный каждой частицей в отдельности. Этот подход дает возможность точного определения коэффициента диффузии наночастиц в жидкости с последующим расчетом их диаметра по уравнению 4 [60].

Преимуществом АТН по сравнению с динамическим светорассеянием является возможность точного анализа полидисперсных 
систем, при этом траектории движения каждой частицы отслеживаются независимо от их размера. Некоторым ограничением метода является необходимость работы с сильно разбавленными системами, что, в свою очередь, может приводить к диссоциации полимерных комплексов на исходные компоненты. Кроме того, данный метод является менее эффективным для частиц с размерами ниже 20-50 нм из-за их малого рассеяния.

Метод АТН использован в работе [56] для исследования комплексов, образованных ПАК и ПВП в метаноле. Выявлено, что формирование комплексов может происходить даже в сильно разбавленных растворах: частицы ИПК с размером 170 нм были выявлены даже при разбавлении 0.01 осново-моль/л растворов исходных полимеров в $10^{5}$ раз. Установлено, что при таком разбавлении образуется до $2 \times 10^{13}$ частиц ИПК на 1 мл дисперсии, т.е., анализ траекторий позволяет определить абсолютную концентрацию частиц в дисперсии, что является одним из преимуществ данного метода.

Помимо определения размеров поликомплексов, АТН может также использоваться для установления наличия специфических взаимодействий в сложных коллоидных системах посредством изучения их диффузионных характеристик. Преимуществом ТАН является возможность отслеживания траекторий движения люминесцентно меченых частиц в жидкости, содержащей нефлуоресцирующие полимеры. Нами исследованы 
диффузионные характеристики люминесцентно меченых силикатных наночастиц, покрытых оболочкой из полиэтиленгликоля (ПЭГилированные частицы) в водных растворах некоторых полимеров, например, ПАК, ПВП, полиэтиленоксида (ПЭО) и гидроксиэтилцеллюлозы (ГЭЦ), одинаковой вязкости [61]. На рис. 3 представлены кривые распределения коэффициента диффузии ПЭГилированных наночастиц в воде и водных растворах различных полимеров. Наиболее медленная диффузия наночастиц наблюдается в растворах ПАК (рис. 3, кривая 3) из-за сильного интерполимерного взаимодействия посредством водородных связей. Наиболее эффективная диффузия имеет место для частиц, диспергированных в растворах ПЭО. Макромолекулы ПЭО не могут специфически взаимодействовать с ПЭГ-модифицированной поверхностью из-за химического сходства их структуры, и их присутствие в растворе замедляет движение наночастиц по сравнению с образцом диспергированном в воде только за счет повышенной вязкости. В воде (рис. 3, кривая 1) модифицированные ПЭГ наночастицы двигаются гораздо быстрее из-за более низкой вязкости по сравнению с растворами полимеров. 




Рис. 3. Распределение модифицированных ПЭГ наночастиц (ПЭГ, 5000 Да) по коэффициенту диффузии в воде (1) и водных растворах полимеров - ГЭЦ (2), ПАК (3), ПВП (4), ПЭО (5) - с постоянной вязкостью 5.10 сП. Из работы [61] с разрешения издательства American Chemical Society.

\section{3. Просвечивающая электронная микроскопия}

Просвечивающая электронная микроскопия (ПЭМ) позволяет получать изображение объектов при прохождении луча ускоренных электронов через тонкий срез образца. ПЭМ дает значительно большее разрешение по сравнению с оптической микроскопией. Данный метод довольно часто используется для исследования наноматериалов. Для достижения хорошего качества изображения наноматериалы должны обладать определенной способностью поглощать ускоренные электроны. Для этого часто 
используют предварительную обработку образца солями некоторых тяжелых металлов (например, уранилацетат), которые сорбируются объектами исследования и придают контраст изображению.

Существенным ограничением ПЭМ является необходимость проведения экспериментов под вакуумом и как следствие - важность использования образцов, не содержащих большое количество воды. Подготовка образцов для таких экспериментов должна включать их обезвоживание. Помимо высушивания взаимодействие таких образцов с поверхностью может, и в весьма значительной степени, изменять их морфологию. Одним из вариантов исследования образцов без их осушки является криопросвечивающая электронная микроскопия (крио-ПЭМ). Отличительной особенностью приготовления образцов для анализа методом криопросвечивающей электронной микроскопии является быстрая витрификация (стеклование) исследуемых водных растворов в жидком этане, при которой вода не кристаллизуется при замораживании, а остается в аморфном состоянии. За счет витрификации, крио-ПЭМ дает информацию свободную от артефактов, связанных с высушиванием или замораживанием образца.

ПЭМ и крио-ПЭМ являются эффективными методами для исследования структурных особенностей полимерных комплексов [62, 63]. ПЭМ была использована нами для исследования структуры ИПК полиакриловой кислоты и метилцеллюлозы (МЦ), образованных в водных растворах при 
различных $\mathrm{pH}$ (рис. 4) [64]. Установлено, что ИПК, формирующиеся в кислых средах, представляют собой сферические наночастицы плотной структуры (рис. 4a, б). Получение качественных ПЭМ изображений не требовало использования контрастирующих агентов. Размеры частиц, образующихся при рН 1.4 и 2.4, были около 80 - 200 нм, в то же время ИПК полученные при рН 3.2 обладали совершенно иной структурой (рис. 4 в). Эти комплексы были гораздо меньшего размера (20-30 нм) и представляли собой наночастицы связанные в сетку посредством волокнообразных фрагментов. По всей вероятности, ИПК, образованные при таком значении $\mathrm{pH}$, являлись “первичными” частицами, стабилизированными от дальнейшей агрегации макромолекулами не участвующего в комплексе полимера.

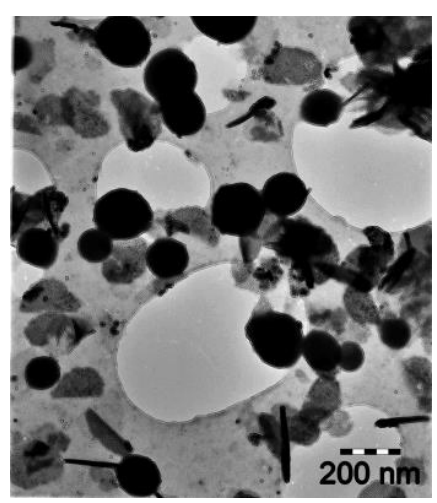

(a)

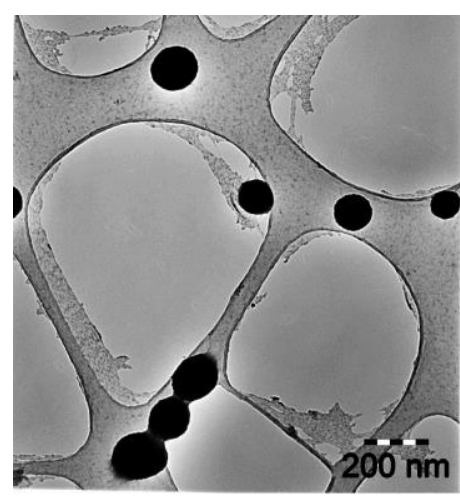

(б)

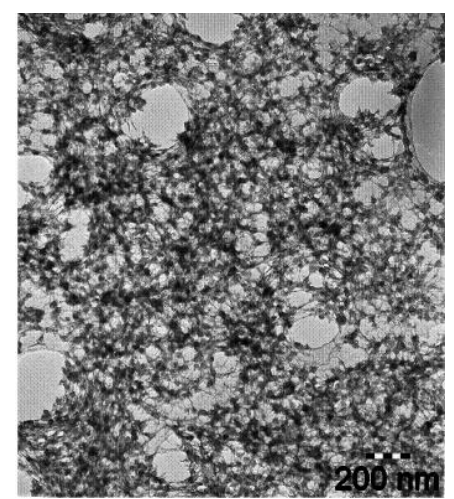

(B)

Рис. 4. Морфология ИПК, полученных смешением 0.2 вес. \% водных растворов ПАК и МЦ (30:70 вес. \%) при рН 1.4 (а), 2.4 (б), и 3.2 (в). Микрофотографии методом ПЭМ. Из работы [64] с разрешения издательства American Chemical Society.

Авторы работы [65] использовали метод крио-ПЭМ для исследования нано-структуры комплексов образованных полиакриловой кислотой и 
катионным липидом - бис(11-ферроценилундецил)-диметил-аммонийбромидом. Авторы установили формирование сферических мультиламеллярных комплексов, имеющих структуру луковиц (рис. 5). Предполагается, что ПАК в структуре таких комплексов внедряется между двумя липидными бислоями.



Рис. 5. Морфология комплексов, образованных при смешении $1 \mathrm{MM}$ растворов ПАК и бис(11ферроценилундецил)-диметиламмоний-бромида.

Микрофотографии получены с помощью крио-ПЭМ-техники. Шкала - 25 нм. Из работы [65] с разрешения издательства American Chemical Society.

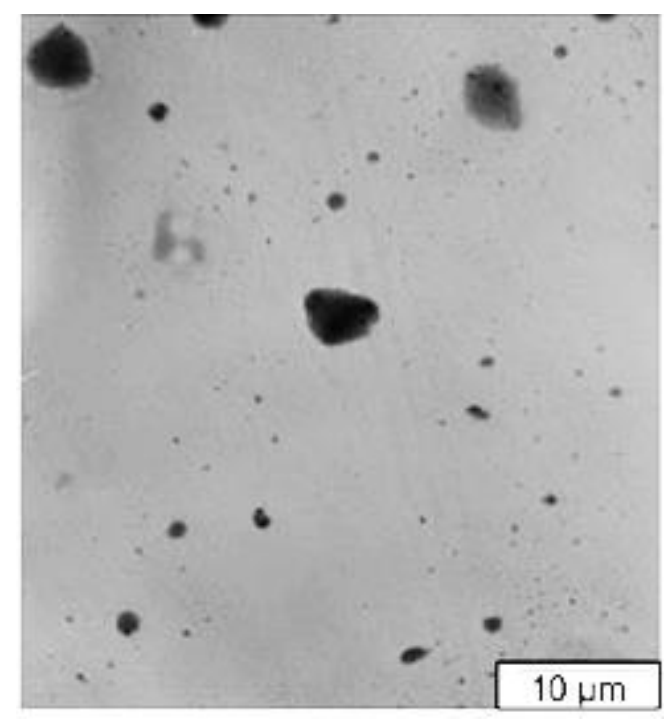

(a)



(б) 




(в)
Рис. 6. Морфология комплексов

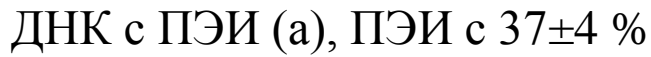
ацетилированных групп (б) и ПЭИ с $102 \pm 8 \%$ ацетилированных групп (в). Соотношение компонентов в комплексе: [ДНК]/[полимер]=1:10 по весу. Микрофотографии комплексов получены методом ПЭМ. Из работы [66] с разрешения издательства Elsevier.

Методом ПЭМ Aravindan с соавторами [66] исследовали влияние химической структуры полиэтиленимина (ПЭИ) на комплексы с ДНК (рис. 6). В этих экспериментах ПЭИ был химически модифицирован путем реакции аминогрупп с уксусным ангидридом (ацетилирование). Введение ацетильных групп в структуру ПЭИ приводило к изменению буферной емкости и гидрофобно-гидрофильного баланса этого полимера, что оказывало существенное влияние на характер его взаимодействия с ДНК. Комплексы немодифицированного ПЭИ (рис. 6а) и полимера с низкой степенью модификации имели сферическую и плотную структуру. ПЭИ с высокой степенью модификации (рис. 6 б) образовывал комплексы с ДНК, обладающие рыхлой структурой (рис. 6 в) и склонностью к агрегации.

Schacher c соавторами [67] исследовали ИПЭК, образованные триблок-сополимером полибутадиен-блок-поли(N-метил-2-винилпиридиний)-блок-полиметакриловая кислота (ПБ-блок-ПМВП-блокПМАК) и диблок-сополимером ПМВП-блок-ПЭО. Методами крио-ПЭМ, 
сканирующей силовой микроскопии, ДРС установлено, что ИПЭК образуют звездо-подобную структуру через 1 час после смешения компонентов, которая преобразуется в течение 10 дней в сферический объект сложной морфологии ядро-оболочка ${ }_{1}$-оболочка 2 -корона.

\section{4. Атомно-силовая микроскопия}

Атомно-силовая микроскопия (АСМ) основана на использовании очень упругого механического наноразмерного зонда - кантилевера, способного «скользить» по образцу и «считывать» рельеф поверхности. АСМ может использоваться для исследования поверхности с разрешением от десятков ангстрем вплоть до атомарного. Принцип работы АСМ основан на регистрации силового взаимодействия между поверхностью исследуемого образца с зондом.

Существует несколько разновидностей и режимов применения метода АСМ в зависимости от поставленных задач. В контактном режиме кантилевер прижимается к образцу и его отклонение вызвано взаимным отталкиванием атомов острия иглы и поверхности в результате перекрывания их электронных оболочек и кулоновского отталкивания ядер. В бесконтактном режиме АCM позволяет измерять силы притяжения между острием сканирующей иглы и образцом [68]. Преимуществом данного метода является возможность проведения исследований живых 
объектов в жидких средах, а также синтетических систем на межфазной границе частица - жидкость.

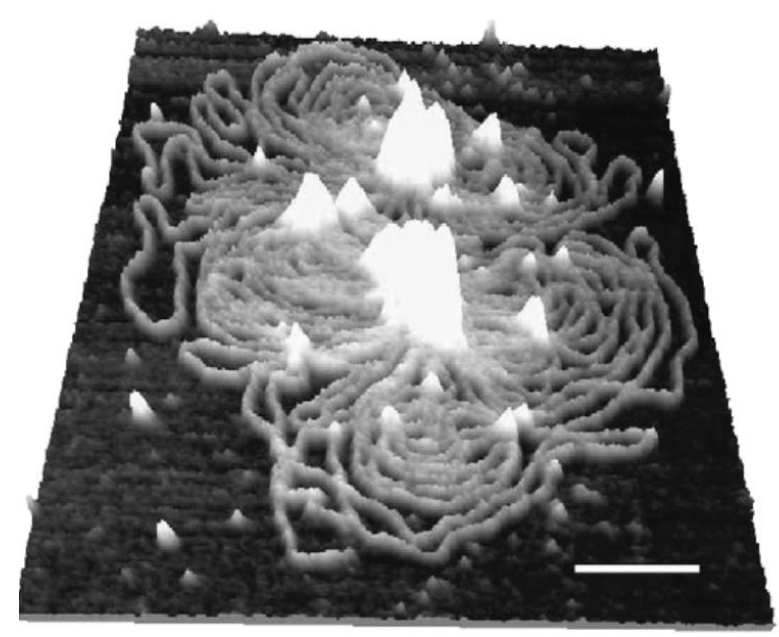

(a)



(б)

Рис. 7. Морфология комплексов ДНК с дендримером DAB (a) и с кватернизированным DAB (б), диспергированных в растворе декстрозы. Соотношение компонентов: дендример/ДНК=5:1. Шкала - $100 \mathrm{Hм}$. Микрофотографии комплексов получены методом АСМ. Из работы [69] с разрешения издательства Elsevier.

Метод АСМ был с успехом использовали Schatzlein с соавторами [69] для исследования структуры комплексов, образованных катионными дендримерами полипропиленимина (серии DAB, с ядром из диаминобутана (DiAminoButane) и их производными с ДНК (рис. 7). Показано, что химически модифицированные дендримеры путем их кватернизирования посредством реакции с йодистым метилом обладают более эффективной способностью образовывать компактные комплексы с ДНК (рис. 7б) по сравнению с исходным DAB (рис. 7a).

Интересное исследование морфологии ИПК, образованных цилиндрическими полиэлектролитными шётками (ЦПЩ) и 
противоположно заряженными линейными полиэлектролитами представлено в работе [70]. Показано, что морфология ИПК, образованных ЦПЩ с линейным полистиролсульфонатом натрия $-\mathbf{\Pi C C}(\mathbf{N a})$, может меняться при изменении соотношения их зарядов. В случае коротких цепей ПСС(Na) с увеличением этого соотношения наблюдали переход от вытянутой червеобразной структуры ИПК до коллапсированных сферических частиц через интермедиаты, имеющие морфологию жемчужного ожерелья. А в случае длинных цепей ПСС(Na) данный переход не имел промежуточной стадии. Кроме того, общей закономерностью данной системы является неоднородное распределение цепей ПСС( $\mathrm{Na})$ между щетками не зависимо от длины линейного полианиона.

\section{5. Малоугловое и ультра-малоугловое рассеяние нейтронов}

Дифракционные методы исследования полимерных систем включают малоугловое (МУРН) и ультра-малоугловое рассеяние нейтронов (УМУРН). Это структурные методы, в которых используется упругое рассеяние пучка на ядерных неоднородностях исследуемых систем, которые представляют собой мотивы, частицы, либо ячейки [71]. Использование одновременно МУРН и УМУРН позволяет изучать структурные уровни организации сложных полимерных систем в широком диапазоне переданных импульсов $q$ от $10^{-5}$ до $1 \AA^{-1}$, содержащих неоднородности на мезоскопическом уровне от 1 нм до нескольких 
десятков микрометров $[72,73]$. Использование особого конструктивного решения, предложенного и реализованного на установке KWS-3 в Научном центре Юлиха [74], позволяет эффективно исследовать рассеяние нейтронов в «самых» малых углах (по-английски - Very Small Angle Scattering) для промежуточного диапазона переданных импульсов $10^{-4}<q$ $<10^{-3} \AA^{-1}$.

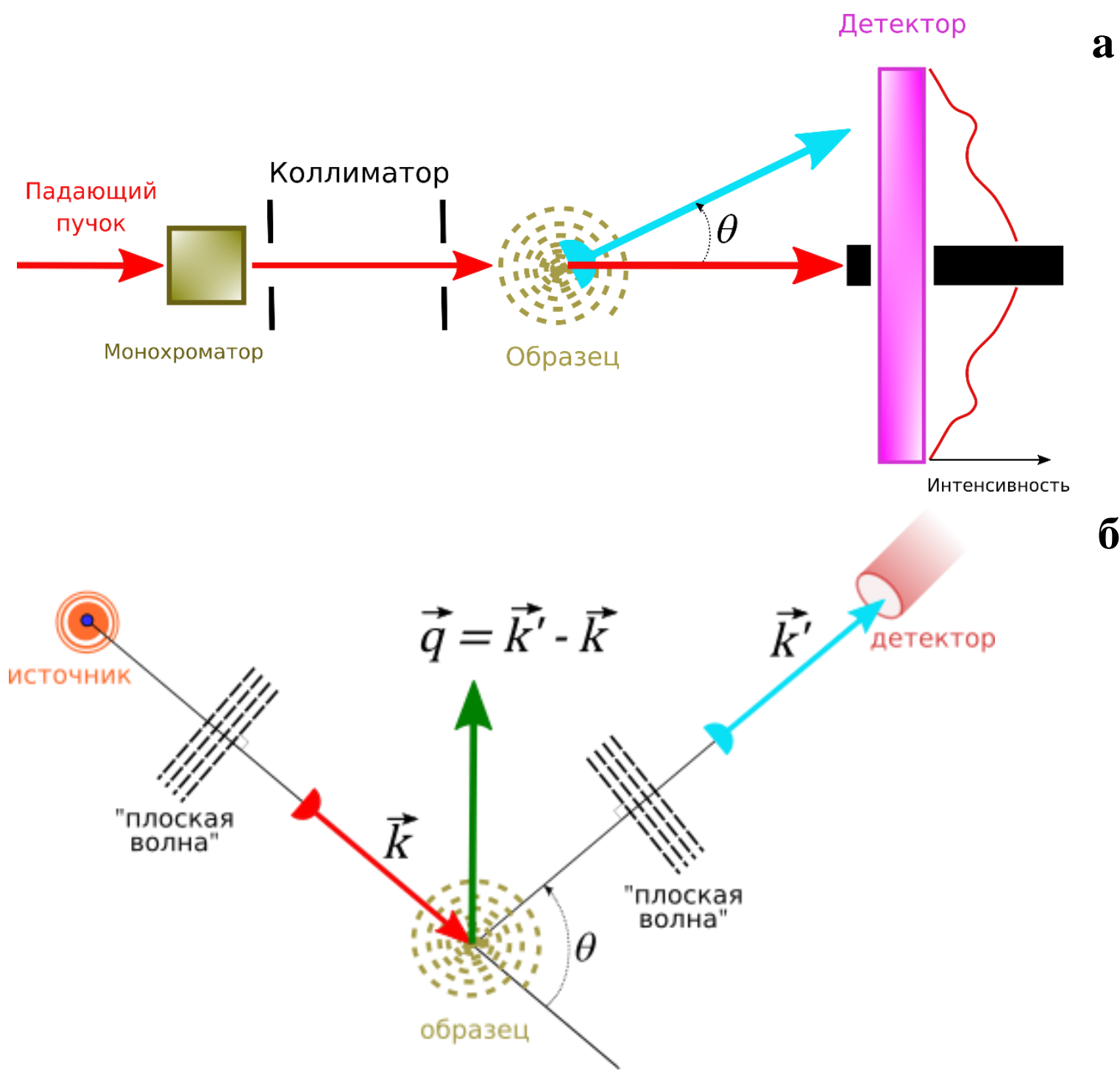

Рис. 8. Схема эксперимента МУРН (а) и процесса рассеяния монохроматического нейтронного пучка (б). 
В эксперименте по малоугловому рассеянию пучок нейтронов направляется на образец, например, раствор полимера или коллоидную дисперсию (рис. 8а). Предварительно он монохроматизируется и коллимируется. Нерассеянные нейтроны поглощаются стопором (заслонкой) в центре детектора. Процесс рассеяния монохроматического излучения можно представить в приближении Фраунгофера (рис. 8б) так: на образец и детектор приходят плоские волны из-за того, что расстояния источник-образец и образец-детектор, соответственно, значительно больше, чем размер образца.

В эксперименте интенсивность рассеянных нейтронов регистрируют как функцию угла рассеяния $\theta$ (рис. 8). Анализ результатов проводят в координатах интенсивность рассеяния $I_{s}$ - переданный импульс $q$. Последний определяется следующей формулой (рис. 8б):

$$
\vec{q}=\vec{k}-\vec{k},
$$

где $\vec{k}$ - импульс падающей волны, $\vec{k}$ - импульс рассеянной волны в системе единиц измерения с $\hbar=\frac{h}{2 \pi} \stackrel{\text { def }}{=} 1, h-$ постоянная Планка. (Часто называют векторные величины $\vec{k}, \vec{k}$ и $\vec{q}$ волновыми векторами, которые, будучи умноженные на величину $\hbar$, становятся импульсами.) Энергия нейтрона при упругом рассеянии не меняется: $\frac{\hbar^{2}|\vec{k}|^{2}}{2 m_{n^{0}}}=\frac{\hbar^{2}|\vec{k}|^{2}}{2 m_{n^{0}}}, m_{n^{0}}=1,674927351$. $10^{-27} \Gamma$ - масса нейтрона. Поэтому для абсолютных значений переданных 
импульсов справедливо $\quad|\vec{k}|=|\vec{k}|$. Тогда на основе несложных геометрических построений равнобедренного треугольника на векторах $\vec{k}$, $\vec{k}$ и играющего роль хорды вектора $\vec{q}$ (рис. $8 б$ ) получают между важными в рассеянии нейтронов физическими величинами соотношение:

$$
q=\frac{4 \pi}{\lambda} \sin \frac{\theta}{2}=\frac{2 \pi}{\lambda} \operatorname{crd} \theta
$$

где $\lambda$ - длина волны нейтронов, а $\operatorname{crd} \theta \stackrel{\text { def }}{=} 2 \sin \frac{\theta}{2}-$ функция хорды, равна длине хорды против угла $\theta$ в единичной окружности. Более крупные наноструктуры наблюдаются при малых углах рассеяния, т.е. в малых $q$.

В эксперименте МУРН и УМУРН получают величину дифференциального сечения рассеяния $d \Sigma(q) / d \Omega$, которая отвечает на вопрос: сколько нейтронов в единицу времени в среднем испытывает рассеяние под определённым углом $\theta$ в телесный угол $d \Omega$ ? По сути, это коэффициент пропорциональности между числом нейтронов, рассеянных в некоторый угол $d \Omega$ за единицу времени, к числу нейтронов, проходящих в единицу времени через единицу площади поперечного сечения исходного пучка. На основе величины $d \Sigma(q) / d \Omega$ можно восстанавливать ядерную рассеивающую плотность неоднородностей исследуемых объектов. Для этого на детекторе (рис. 8) измеряют $q$-распределение интенсивностей или потоков рассеянных нейтронов после образца, $I(q)$, и для сравнения без него, $I_{\text {ср }}(q)$. Последнее необходимо, поскольку есть фон зала, а арматура 
установки, кварцевые кюветы и сама среда, в которую помещена исследуемая система, могут рассеивать $[30,75,76]$.

Если получены двумерные изотропные спектры, их обычно азимутально усредняют и приводят к абсолютным значениям путем нормировки на сечение некогерентного рассеяния эталона, например полиметилметакрилата (плексигласа), с учетом эффективности детектора [77] и толщины каждого из образцов. Для предварительной обработки данных используют специальное программное обеспечение, например, QtiKWS [78].

Необходимо также учитывать, что величина $d \Sigma(q) / d \Omega$ связана с функцией разрешения установки $F(q)$ через одномерную «смазывающую» свертку, подходящую для азимутально изотропных измерений $[79,80]$ :

$$
\frac{d \Sigma(q)}{d \Omega}=\int_{-\infty}^{+\infty} d q_{1} F_{1 D}\left(q_{1}\right) \frac{d \Sigma\left(\left|q-q_{1}\right|\right)}{d \Omega},
$$

где $F_{1 \mathrm{D}}(q)$ обычно аппроксимируется функцией Гаусса. В случае использования позиционно-чувствительного детектора для азимутально анизотропного рассеяния нужен двумерный аналог преобразования 6 с функцией $F_{2 \mathrm{D}}(q)[77$ (уравнения 3 и 4)].

Использование комплекса методов МУРН, УМУРН и рассеяния нейтронов при «самых» малых углах позволяет получить полную структурную картину как для растворов ИПК, так и сложных композиционных материалов в диапазоне приблизительно от 1 нм до 
20 мкм $[30,75,76]$. Нужно отметить, что метод спин-эхо малоуглового рассеяния нейтронов (СЭМУРН) позволяет измерять исследуемые неоднородности, например, для взаимопроникающей полимерной сетки полимерного композиционного гидрогеля в прямом пространстве размеров, а не обратном пространстве волновых векторов, вплоть до 20 мкм, что дает преимущество в наглядности [31].

Дейтерирование отдельных фрагментов исследуемых объектов позволяет варьировать контрастом и получать информацию об организации и структуре сложных полимерных систем. В некоторых случаях варьирование контраста может также быть достигнуто путем смешения дейтерированных и протонированных растворителей, например, «тяжелой» и обычной воды $\left(\mathrm{D}_{2} \mathrm{O}: \mathrm{H}_{2} \mathrm{O}\right)$ и других смесей $[79,81]$. Использование метода МУРН с вариацией контраста в системе позволяет исследовать отдельные компоненты в структуре полимерных комплексов. В работе Zeghal и Auvray [82] применен метод вариации контраста при исследовании структуры ИПК, образованных полиметакриловой кислотой (ПМАК) и ПЭО при различных степенях нейтрализации ПМАК. В экспериментах использовали дейтерированную ПМАК, частичная нейтрализация которой достигалась добавлением разного количества $\mathrm{NaOH}$. Было установлено, что при степени нейтрализации ПМАК $\alpha=\left[\mathrm{COO}^{-}\right] /[$ИГ $]=10$ \% (ИГ-ионогенные группы в ПМАК) образование ИПК не происходит и конформации каждого полимера в смеси близки к тем, что наблюдаются при отсутствии второго 
компонента. При более низких значениях $\alpha$ комплексообразование приводит к изменению конформации как ПМАК, так и ПЭО с образованием компактных частиц ИПК.

В работе Merta с соавторами [83] методом МУРН исследована структура комплексов, образованных катионным крахмалом и рядом анионных ПАВ (пальмитат натрия, додеканоат натрия, деканоат натрия и октаноат натрия). Установлено, что макромолекулы катионного крахмала имеют спиральную конформацию. При их ассоциации с ПАВ наблюдается образование более компактных цилиндрических агрегатов, в которых молекулы ПАВ находятся внутри спиральной структуры.

В работе Sotiropoulou с соавторами [84] метод МУРН использовался для установления структурных особенностей комплексов, образованных ПАК и сополимером акриловой кислоты и 2-акриламидо-2-метил-1пропансульфоновой кислоты, содержащими привитые цепи N,Nдиметилакриламида (АК-со-АМПС-прив-ПДМААм) при рН < 3.75 (рис. 9). Установлено, что в результате комплексообразования происходит формирование отрицательно заряженных коллоидных частиц размером $165 \AA$, состоящих из гидрофобного ядра и гидрофильной опушки (рис. 9). Ядро этих частиц представляет собой компактные комплексы ПДМААм с ПАК, стабилизированные водородными связями. Эти частицы не подвергаются агрегации из-за стабилизации отрицательно заряженными цепями АК-со-АМПС, которые формируют гидрофильную опушку. 

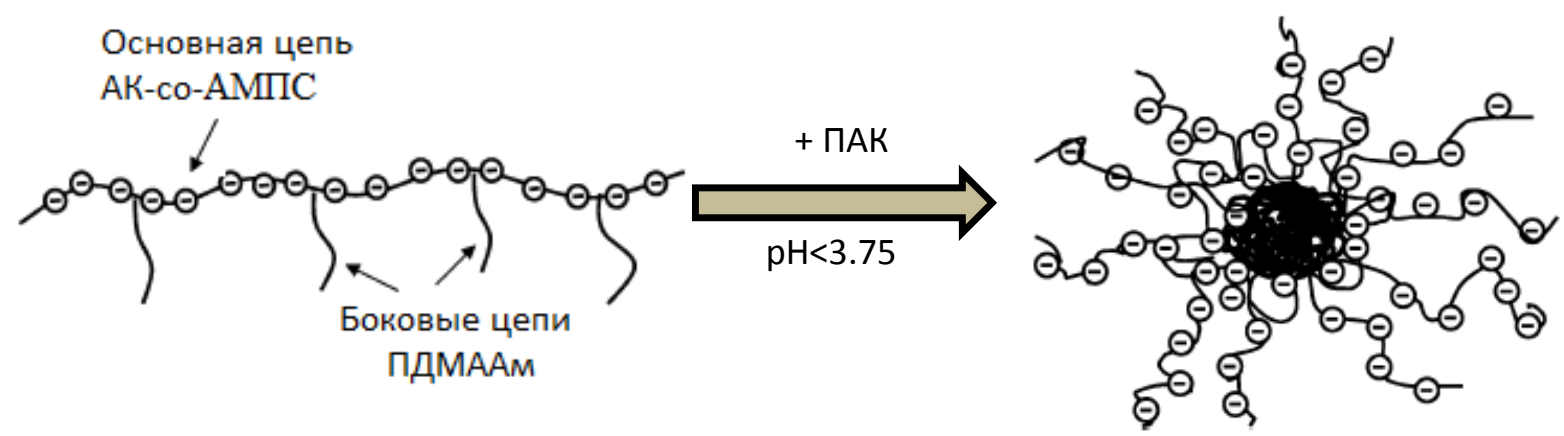

Рис. 9. Схематическое изображение структуры АК-со-АМПС-привПДМААм и их комплекса с ПАК. Из работы [84] с разрешения издательства American Chemical Society. Адаптирован к русскому изданию.

Избыточное содержание (концентрирование) малых молекул, олигомеров на поверхности белков по сравнению с их концентрацией в растворе за счет образования ИПК влияет на структуру и функциональные свойства биополимеров.

Rajapaksha c соавторами [85] использовал малоугловое рассеяние для изучения влияния такого концентрирования на размеры протеинового комплекса с участием супероксиддисмутазы (СОД). Концентрирование происходило с участием ПЭО (400 Да), триэтиленгликоля (ТЭГ), метил- $\alpha-$ гликозида $(\boldsymbol{\alpha}-\mathbf{M \Gamma})$ и триметиламин- $n$-оксида (ТМАО). В работе [85] авторы использовали подход, предложенный Свергуном [86], в котором «играют» на разных механизмах контраста, достигаемого в МУРН и малоугловом рассеянии рентгеновских лучей (МУРР) для независимой оценки вклада гидратной оболочки. Комплексное использование МУРН и МУРР позволило авторам однозначно связать явное изменение радиуса инерции, $R_{\mathrm{g}}$, с изменением в структуре СОД. Так, для 40\%-раствора ПЭО авторы 
нашли, что объем СОД уменьшается на 9\%. Принимая во внимание осмотическое давление за счет ПЭО, такая деформация введёт к образованию сильно сжатой конформации биополимера. Малоугловое рассеяние в присутствие ТЭГ навело на мысль, что дальнейшей деформации - за пределы 9\% от объема - может мешать резко возрастающее конформационное сопротивление.

\section{6. Турбидиметрия, абсорбционная электронная}

спектроскопия, и фотолюминесцентные методы

Абсорбционная электронная спектроскопия и турбидиметрия остаются классическими методами исследования комплексообразования макромолекул в растворе, поскольку позволяют получать оригинальные данные на вновь синтезированных полимерных системах. Так, в работе [87] авторы исследовали реакции замещения между слабосшитыми анионными гидрогелями, образованными сеточными либо полиакрилатом натрия, либо поли(2-акриламидо-2-метил-1-пропансульфонатом) натрия $\quad$ и нестехиометрическим ИПЭК, образованным линейным полиакрилатом натрия - ПА(Na) - и лиофилизованным поли(N,N'-диаллил-N,N'диметиламмоний хлоридом) (ПДМАХ) в водной среде. Нестехиометрические ИПЭК состоят из амфифильных блоков и существенно отличаются от ди-, три- и многоблочных сополимеров [88]. Реакцию образования ИПЭК авторы [87] изучали методом турбидиметрии. 
Оказалось, что нестехиометрический ИПЭК (ПА(Na)/ПДМАХ) остается растворим для мольных соотношений звеньев $[\mathrm{A}(\mathrm{Na})]:[Д \mathrm{MAX}] \leq 0.5$. Когда содержание звеньев ДМАХ перестает превосходить двукратный избыток звеньев ПА(Na) раствор становится мутным. Турбидиметрией авторы изучили поведение ИПЭК (ПА(Na)/ПДМАХ) при соотношении $[\mathrm{A}(\mathrm{Na})]:[Д \mathrm{MAX}]=0,2$ в зависимости от ионной силы, варьируя мольную концентрацию $\mathrm{NaCl}$ при [ДМАХ] $=10^{-3}$ осн.-мол./л, $\mathrm{pH} 9.5, \mathrm{~T}=20^{\circ} \mathrm{C}$. При низкой ионной силе $[\mathrm{NaCl}]<0.06 \mathrm{M}$ раствор оставался прозрачным, однако мутность раствора достигала максимума при $[\mathrm{NaCl}]=0.27$ М. Подобное поведение типично для нестехиометрических ИПЭК, когда потеря растворимости сопровождается диспропорционированием частиц поликомплекса и образованием нерастворимого стехиометрического ИПЭК [3]. Новый и нетривиальный результат - карбоксилатная полимерная сетка включает линейный поликатион посредством образования стехиометрического комплекса, при этом коллапсируя [87].

Методы фотолюминесцентной спектроскопии в течение многих лет успешно используются для исследования процессов комплексообразования полимеров. Одно из их преимуществ, например, перед абсорбционной электронной спектроскопией в видимом и УФ-диапазонах заключается в возможности исследовать разбавленные растворы полимерных систем, т.е. возможность перейти к мономолекулярному уровню. Данным методам посвящен ряд обзоров $[89,90]$, в которых подробно рассмотрены подходы 
для изучения полимерных комплексов. В связи с этим мы не будем останавливаться на анализе всех возможных подходов, ограничившись описанием несколько наиболее эффективных в изучении образования и функционирования ИПК - образование и разрушение комплексов с переносом заряда, способных люминесцировать, тушение люминесценции и поляризованная люминесценция (ПЛ).

Метод флуоресиентных зондов; подразумевает введение флуоресцентных красителей («зондов») в структуру объектов с последующим исследованием фотолюминесцентных характеристик таких зондов (спектров, длительности и квантового выхода люминесценции). Такой подход позволяет изучать конформационные перестройки в полимерных системах как синтетического так и природного происхождения [91].

Для исследования эффектов $\mathrm{pH}$ на структуру ИПК, стабилизированных водородными связями, Хуторянский с соавторами [9294] использовали в качестве флуоресцентного зонда (Ф3) пирен ароматическое соединение гидрофобной природы, способное менять спектры флюоресценции в зависимости от полярности окружения (например, растворителя). В спектре пирена имеются два характерных вибрационных пика (373 и 383 нм), отношение интенсивностей которых ( $\left.\mathrm{I}_{383} / \mathrm{I}_{373}\right)$ постоянно для среды определенной полярности. Для пирена, 
солюбилизированного в воде, это отношение составляет 0.60-0.64. Увеличение величины $\mathrm{I}_{383} / \mathrm{I}_{373}$ свидетельствует о снижении полярности среды или, например, об образовании гидрофобных доменов в ходе самосборки макромолекул полимера.

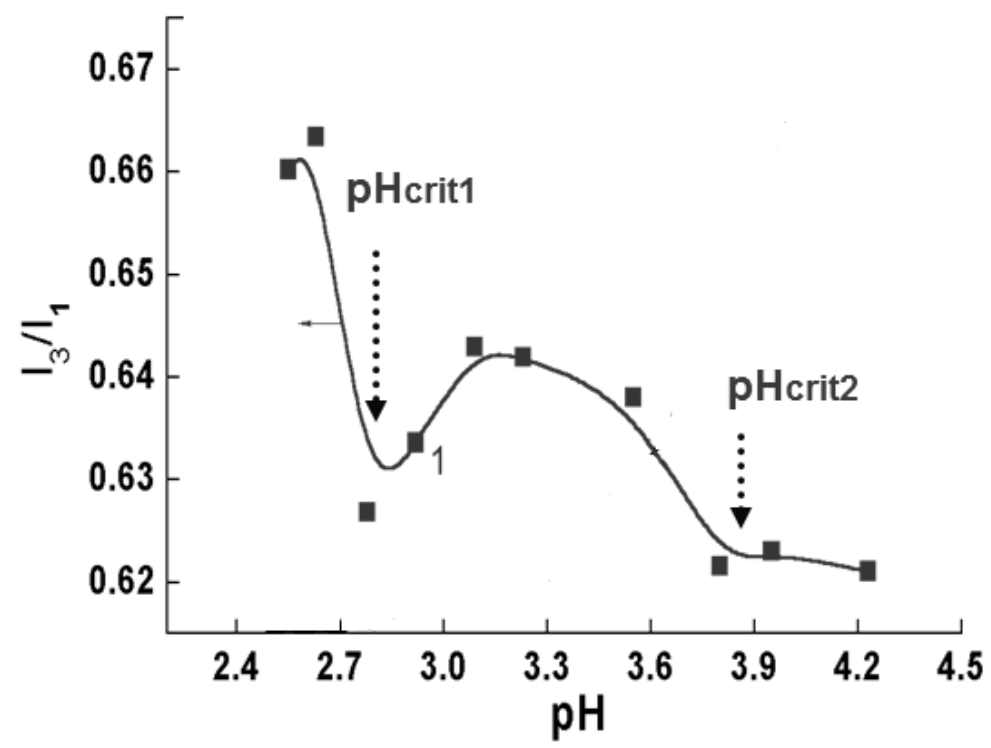

Рис. 10. Зависимость $\mathrm{I}_{383} / \mathrm{I}_{373}$ (или $\mathrm{I}_{3} / \mathrm{I}_{1}$ ) в спектрах пирена, солюбилизированного в эквимольной смеси полиакриловой кислоты и поливинилового спирта. Концентрации полимеров 0.01 М. Из работы [93] с разрешения издательства Wiley \& Sons.

При исследовании характера изменения $\mathrm{I}_{383} / \mathrm{I}_{373}$ в спектрах пирена, солюбилизированного в растворах смесей поликарбоновых кислот с неионогенными полимерами с разными значениями $\mathrm{pH}$, была установлена интересная закономерность [92-94] (рис. 10). На кривой зависимости $\mathrm{I}_{383} / \mathrm{I}_{373}$ от $\mathrm{pH}$ имеют место два минимума. Первый - соответствует

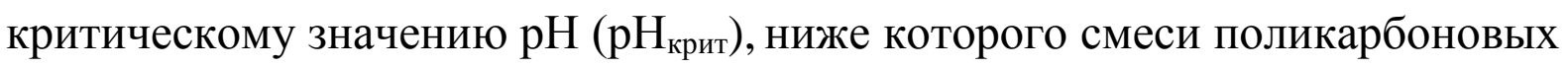
кислот с неионогенными полимерами начинают резко мутнеть. Ранее [95, 
96] нами было предложено рассматривать величину $\mathrm{pH}_{\text {крит }}$ как критерий способности полимерной системы к комплексообразованию: высокие значения $\mathrm{pH}_{\text {крит }}$ соответствуют повышенной склонности смеси полимеров к

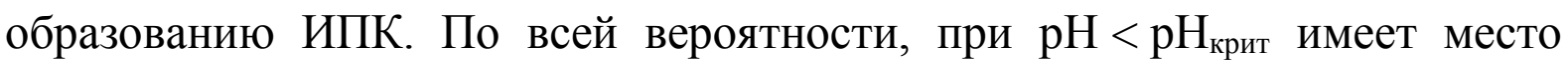
формирование ИПК гидрофобной природы, что приводит к возрастанию величин $I_{383} / I_{373}$. При повышении $\mathrm{pH}$ выше $\mathrm{pH}_{\text {крит }}$ сначала наблюдается рост значений $\mathrm{I}_{383} / \mathrm{I}_{373}$, затем их снижение, и далее эти величины либо не меняются, либо опять увеличиваются. Можно полагать, что в области между двумя минимумами на кривой $\mathrm{I}_{383} / \mathrm{I}_{373}-\mathrm{pH}$ имеет место перестройка структуры ИПК и формирование ассоциата с более выраженной гидрофильностью. При рН выше второго минимума вероятно наблюдается полная диссоциация комплекса на исходные компоненты. Подобные изменения величин $\mathrm{I}_{383} / \mathrm{I}_{373}$ от $\mathrm{pH}$ наблюдались нами для ряда систем на основе смесей полиакриловой кислоты с полиэтиленоксидом [92], поливиниловым спиртом [93], и гидроксипропилцеллюлозы [94]. По всей вероятности, такая закономерность характерна для всех смесей поликарбоновых кислот с неионогенными полимерами. Измерения такого рода позволяют определить области переходов между гидрофобными частицами ИПК, гидрофильным ассоциатом и свободными макромолекулами в смеси полимеров.

В работе Пергушова с соавторами [97] исследованы мицеллярные ИПЭК на основе диблок-сополимера полиизобутилена и полиметакрилата 
натрия (ПИБ-блок-ПМА(Na) с поли(N-этил-4-винилпиридиний бромидом) (ПЭВПБ) с использованием пиренового зонда, а также проведено сравнение с комплексами гомополимеров ПМА(Na)-ПЭВПБ. Установлено, что отношение интенсивностей пиков $\mathrm{I}_{383} / \mathrm{I}_{373}$, наблюдаемое для комплексов диблоксополимера составило 0.61, что выше, чем величина $\mathrm{I}_{383} / \mathrm{I}_{373} \cong 0.54$, наблюдаемая в чистом буфере $(0.05 \mathrm{M} \mathrm{NaCl}, 0.01$ Tris $)$. Данные наблюдения указывают на то, что пирен солюбилизируется в частицах ИПЭК. Сравнительные эксперименты, проведённые с растворами исходных полимеров, а также поликомплексов ПМА(Na)-ПЭВПБ, указывают на отсутствие солюбилизации пирена: отношение $\mathrm{I}_{383} / \mathrm{I}_{373}$ в таких системах было близко к 0.54. Солюбилизация пирена также наблюдалась в мицеллярном растворе диблок-сополимера. Однако, отношение I383/I373 в растворе ИПЭК (ПИБ-блок-ПМА(Na)—ПЭВПБ) было ниже по сравнению с величиной $\mathrm{I}_{383} / \mathrm{I}_{373}$, полученной в растворе ПИБ-блокПМА(Na) $\left(\mathrm{I}_{383} / \mathrm{I}_{373} \cong 0.69\right)$. Таким образом, на основе полученных данных авторы [97] пришли к выводу, что структура ИПЭК (ПИБ-блок-ПМА(Na)— ПЭВПБ) имеет структуру луковицы. Данная структура состоит из гидрофобного ядра ПИБ, окруженного оболочкой, образованной при взаимодействии противоположно заряженных полиэлектролитных фрагментов ПМА(Na)-ПЭВПБ, а также ионной короной, состоящей из 
полиэлектролитных фрагментов ПMА(Na), не вовлеченных в комплексообразование.

Метод поляризованной люминесиенц̧ии. Структурообразование в растворах индивидуальных макромолекул (внутримолекулярные переходы типа клубок-глобула, клубок - компактная структура, клубок - спираль) или в многокомпонентных полимерных системах (формирование интерполимерных комплексов различного типа, комплексов полимер ПАВ или БАВ, металлполимерных комплексов) связано с изменением внутри- или межмолекулярных взаимодействий различного типа (водородных связей, гидрофобных взаимодействий неполярных групп в воде, электростатических взаимодействий заряженных групп). Образование или разрушение внутри- и межмолекулярных контактов приводит к изменению микроброуновского движения полимерных цепей, внутримолекулярной подвижности (ВМП). Поскольку длительность этих взаимодействий определяется наносекундным интервалом, то наносекундные времена релаксации $\tau_{B M \Pi,}$ характеризующие внутримолекулярную подвижность участков цепи макромолекулы, оказываются чувствительным индикатором изменения структурной организации как индивидуальных макромолекул в растворе при изменении внешних параметров, так и взаимодействующих макромолекул в многокомпонентных полимерных системах. 
Для изучения наносекундной динамики (мелко- и среднемасштабных движений) макромолекул в растворе и блоке используют различные методы: ПЛ, поглощение ультразвука, ядерная магнитная релаксация, релаксация дипольной поляризации в переменных полях [98-111], нейтронная спин-эхо спектроскопия [112-114], нейтронная спектроскопия обратного рассеяния [115]. Метод ПЛ позволяет на основе оценки изменений поляризации люминесценции растворов полимеров с ковалентноприсоединенными люминесцирующими метками (ЛМ)

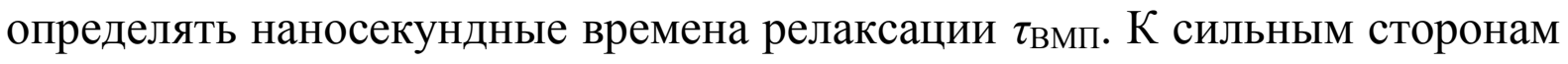
метода ПЛ при изучении ИПК относят возможность обеспечить мономолекулярный уровень исследования растворов полимеров, возможность варьирования химической природы растворителя (органические, водные), возможность изучения многокомпонентных полимерных систем покомпонентно.

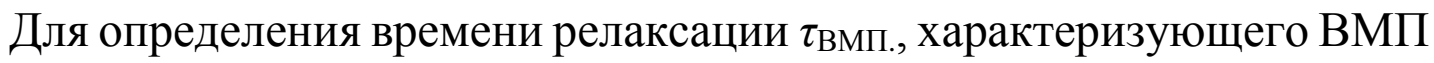
макромолекул в растворе, в методе ПЛ используют соотношение:

$$
\tau_{B M \Pi}=\frac{3\left(1 / P_{0^{\prime}}+1 / 3\right) \tau_{\phi}}{1 / P-1 / P_{0^{\prime}}},
$$

где $1 / P$ - обратная величина поляризации люминесценции раствора ПММА, $1 / P_{0}^{\prime}$ - параметр, характеризующий высокочастотные крутильноколебательные движения ЛМ, и $\tau_{\phi}$ - длительность люминесценции.

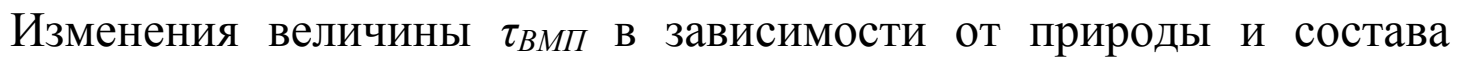
полимера, а также внешних условий, таких как температура, $\mathrm{pH}$, ионная 
сила раствора и т.д. отражают изменения (перераспределение) внутри- и межмолекулярных взаимодействий, которые определяют, с одной стороны, конформационные превращения макромолекул, а с другой, - формирование надмолекулярных структур. В связи с изложенным выше этот подход широко используется для изучения многокомпонентных полимерных систем, т.к. позволяет следить за изменением релаксационных свойств каждого компонента системы, выделяя исследуемый компонент с помощью ковалентно присоединенной люминесцирующей метки [90].

В работах Ануфриевой с соавторами [17, 18] методом ПЛ изучено формирование, структура и стабильности СПК в растворах ПММА и молекулярные механизмы формирования СПК, влияние стереорегулярности, длины полимерных цепей ПММА, влияние сомономерных звеньев, а также влияние природы растворителя и температуры среды на взаимодействие стерически комплементарных макромолекул ПММА. Раскрытие молекулярных механизмов влияния стереорегулярного строения макромолекул ПММА на образование СПК в растворе может быть осуществлено только на молекулярном уровне исследования, когда не существует перекрывания макромолекулярных клубков, т. е. в разбавленных растворах. В работах $[17,18]$ показано, что в условиях разбавленного раствора ПММА (до 0,001\%) при добавлении изоПММА к синдио-ПММА происходит образование множественных контактов между стерически комплементарными участками макромолекул. 
Высокая чувствительность метода ПЛ к образованию интерполимерных комплексов основана на возможности определения значительного (до одного - двух порядков) увеличения времён релаксации $\tau_{\text {вмп, }}$ характеризующих ВМП макромолекул каждого из компонентов, в которой отражается формирование множественных межмакромолекулярных контактов. В методе ПЛ можно поочерёдно исследовать каждый компонент системы, используя полимеры с ковалентно присоединённой ЛМ:

$$
\begin{aligned}
& \text { синдио }(\% s) \text {-ПММА* +изо }(\% i) \text {-ПММА } \rightarrow \text { СПК }\left(\% s^{*}-\% i\right) \\
& \text { синдио }(\% s) \text {-ПММА + изо(\%i)-ПММА* } \rightarrow \text { СПК }\left(\% s-\% i^{*}\right)
\end{aligned}
$$

Люминесцентно меченый компонент обозначен звёздочкой (*), символами $\% s$ и \% условно обозначены, соответственно, выраженные в процентах доля синдиотактических триад в синдио-ПММА и доля изотактических триад в изо-ПММА. В качестве ЛМ использовали мономерные звенья, содержащие люминесцирующую группу (ЛГ) антраценовой структуры, варьируя её положение относительно основной полимерной цепи: в боковом радикале, на конце (антраценовое ядро присоединено по 9-му положению атома углерода), либо в основной цепи (антраценовое ядро присоединено по 9-му и 10-му положениям). Кроме того, варьировали химическое строение ЛМ, т.е. мономерного звена, несущего ЛГ: наличие или отсутствие метильных групп, длину и химическое строение бокового радикала. 



Рис. 11. Схема образования стереополикомплексов между синдио- и изотактическим ПММА: последовательность r-диад и m-диад в синдио- и изотактическом ПММА, соответственно (а); локальная структура комплекса в хороших (б) и плохих (в) растворителях.

При исследовании влияния природы растворителя на образование СПК в разбавленном растворе ПММА и на особенности надмолекулярной структуры, образуемой макромолекулами ПММА различного стереохимического строения, показано, что в растворителях плохого термодинамического качества образуется двутяжевая спиральная 
структура: гибкая макромолекула изо-ПММА наматывается на более жесткую цепь синдио-ПММА. В растворителях хорошего термодинамического качества возникает структура с редкими двутяжевыми участками, стабилизированными за счет вандерваальсовских сил (рис. 11).

В работе [116] методом ПЛ исследовано структурообразование в водных растворах термочувствительных полимеров в присутствии заряженного полиэлектролита. Показано, что при добавлении заряженного полиэлектролита - сополимера $\mathrm{N}$-винилкапролактама с заряженными звеньями кротоновой кислоты - структурообразование в водных растворах термочувствительных полимеров не сопровождается фазовым разделением pacтвора. В этих условиях при температуре выше температуры структурного перехода в макромолекулах термочувствительного полимера образуется глобула. Но при этом наносекундная подвижность заряженного полиэлектролита не изменяется в присутствии глобулярных структур, что указывает на отсутствие межмолекулярных контактов наносекундной длительности заряженного полиэлектролита с макромолекулярными глобулами.

В работе [117] метод поляризованной люминесценции (ПЛ) был применен для исследования комплексообразующих и конформационных свойств статистических термочувствительных сополимеров $\mathrm{N}$ винилпирролидона и N-винилкапролактама (BK). Было установлено, что при повышении температуры времена релаксации $\tau_{\text {Вмп }}\left(25^{\circ}\right)$ увеличиваются 
и тем значительнее, чем выше содержание звеньев ВК. Максимальный рост значений $\tau_{\mathrm{BM \Pi}}\left(25^{\circ}\right)$ от 20 до 170 нс, наблюдаемый для сополимера, содержащего 85 мол. \% звеньев ВК, происходит в относительно узком температурном интервале $-43-48{ }^{\circ} \mathrm{C} . \mathrm{B}$ этих условиях формируется более компактная по сравнению с гомополимером ПВК структура, характеризуемая временами $\tau_{\mathrm{BM \Pi}}\left(25^{\circ}\right)=100 \mathrm{Hc}$.

Структурообразование в макромолекулах исследованных сополимеров, наблюдаемое при повышении температуры, приводит к изменению их комплексообразующих свойств. В модельных экспериментах было исследовано связывание низкомолекулярного люминесцирующего индикатора Акридинового оранжевого (АО):

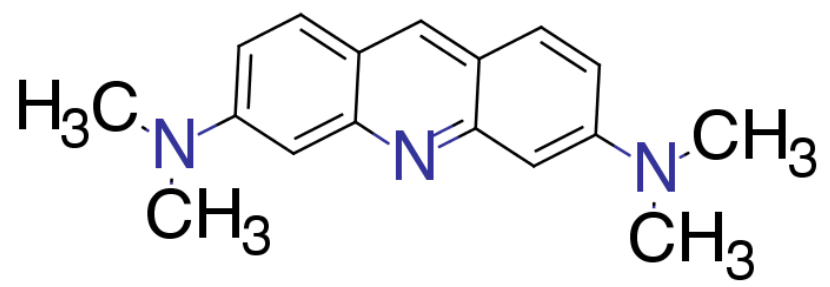

В свободном состоянии времена релаксации таких люминесцирующих молекул составляют $0,1-0,01$ нс. При связывании их макромолекулами значения $\tau_{\mathrm{BM}}\left(25^{\circ}\right)$ возрастают на 2 и более порядков. Это позволяет на основе измерения поляризации люминесценции свободного и связанного $\mathrm{AO}$ определять степень его связывания, $\theta_{A O}$, сополимерами при разных температурах, используя уравнение

$$
\theta_{A O}=\frac{1 / P-1 / P_{\text {своб }}}{1 / P_{\text {своб }}-1 / P_{\text {связ }}},
$$

в котором $1 / P, 1 / P_{\text {своб }}, 1 / P_{\text {связ }}$ - обратные величины поляризации 
люминесценции исследуемого раствора, а также растворов, содержащих свободные и полностью связанные ионы АО, соответственно.

Оказалось, что при $25^{\circ} \mathrm{C}$ величина $\theta_{A O}$ не превышает $5 \%$, а при нагревании водных растворов сополимеров выше $40{ }^{\circ} \mathrm{C}$ доля связанного АО растет и достигает 40\% для сополимера, содержащего 85 мол. \% звеньев ВК. Таким образом, использование люминесцентно меченых макромолекул и низкомолекулярных люминесцирующих индикаторов (зондов) позволяет изучать изменение как структурно-динамических характеристик термочувствительных (со)полимеров, так и функциональных свойств.

В работе [118] исследовано взаимодействие термочувствительного звездообразного полимера с центральным трет-бутилкаликс[8]ареновым звеном и лучами поли(N-изобутироилэтиленимин)полиметакриловой кислотой (темновой и люминесцентно меченой) в водных растворах. Анализ полученных данных позволил сделать заключение о том, что в растворе происходит формирование комплекса, представляющего собой мицеллу со смешанной полимерной короной, компоненты которой образуют интерполимерный комплекс состава 1:1, стабилизированный Н-связями и гидрофобными взаимодействиями. Растворы образующихся комплексов остаются прозрачными при повышении температуры вплоть до $80^{\circ} \mathrm{C}$, в отличие от растворов индивидуального полимера трет-бутилкаликс[8]ареновым звеном и лучами 
поли(N-изобутироилэтиленимин)- $\omega$-пиперазина, для которых температура помутнения $0.05 \%$ раствора составляет $43^{\circ} \mathrm{C}$.

Авторами работы [119] синтезирован сополиимид с регулярно привитыми боковыми цепями ПАК и люминесцентно меченый аналог, содержащий антраценовую ЛМ, ковалентно присоединенную к привитым цепям. Средняя степень поликонденсации основной полиимидной цепи $c a$. 16, средняя степень полимеризации привитых боковых цепей ПАК $c a .100$.

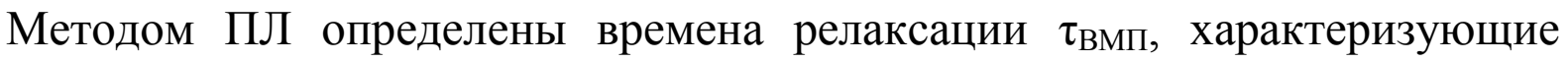
подвижность участков боковых цепей в растворителях различного термодинамического качества по отношению к основным и боковым цепям. Показано, что в “общем” для основной и привитых цепей растворителе

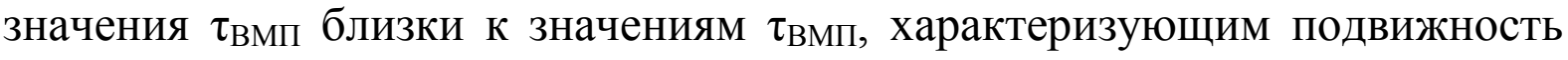
линейных полиметакрилатных цепей. В селективных растворителях

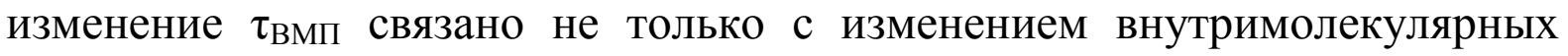
взаимодействий, но и с гетерогенностью динамических характеристик участков привитых цепей, расположенных на разном расстоянии от точки прививки. Далее в работе [120] исследован процесс формирования и структурная организация ИПК, образованных макромолекулами ПВП и цепями ПАК, привитыми к полиимиду. ЛМ антраценовой структуры была поочередно ковалентно присоединена к обоим полимерам. Получены времена релаксации $\tau_{B M \Pi,}$ характеризующие внутримолекулярную 
подвижность каждого компонента в ИПК, в зависимости от состава системы.

Метод тушения люминесиенции.

В МПК, т.е. комплексе металлического иона с полимерным лигандом, активный центр - это лишь мельчайшая часть трехмерной полимерной системы. Поэтому комплексообразующая способность и физикохимические свойства системы прежде всего зависят от характеристик макромолекулярной матрицы [121].

Паутовым с соавторами предложен способ количественной оценки эффективности образования МПК ионами переходных металлов с карбоксилсодержащими (со)полимерами в разбавленных растворах на основе эффекта тушения ионами переходных металлов люминесценции макромолекул с люминесцентными метками [122]. В результате был предложен метод [123] определения равновесных констант устойчивости комплексов $\mathrm{Ag}^{+}, \mathrm{Cu}^{2+}$ и $\mathrm{Ni}^{2+}$ с сополимерами 2-деокси-2-метакриламидо-Dглюкозы (МАГ) и метакриловой или акриловой кислоты (МАК или АК) в водных и водно-солевых средах. В работе [123] предварительно синтезировали люминесцентно меченые сополимеры свободнорадикальной сополимеризацией МАГ и МАК или АК с 9-антрилметилметакриламидом в растворе диметилформамида: 


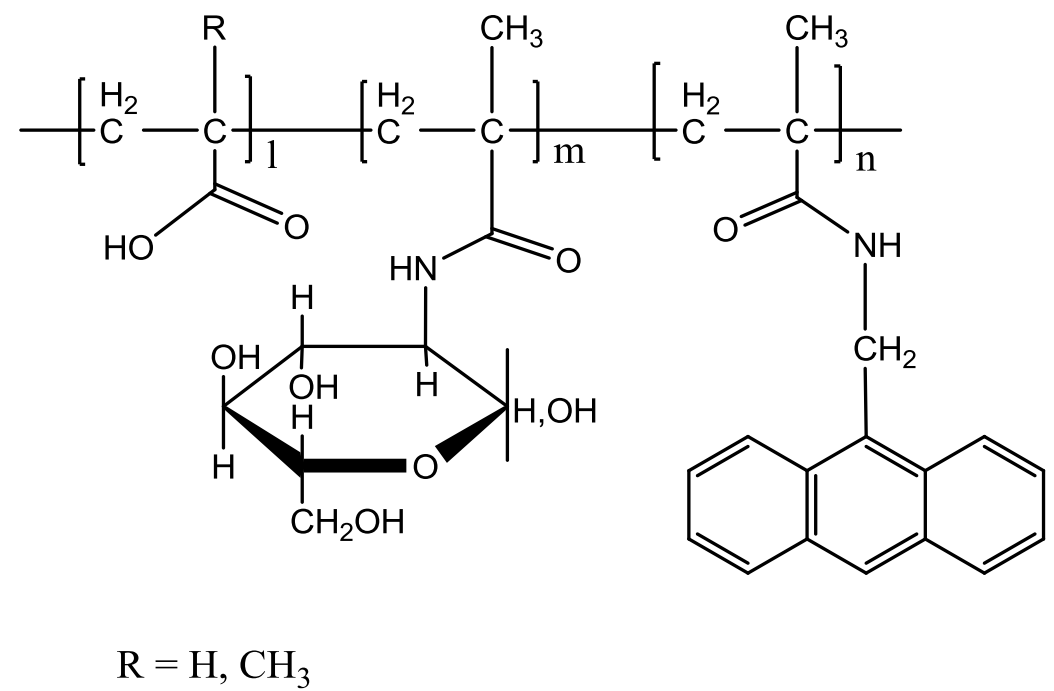

Эффект тушения люминесценции возможно оценивать по изменению интенсивности максимумов полосы люминесценции групп антраценовой структуры ( $\approx 390,413$ и 440 нм) и по изменению интегральной интенсивности спектра в интервале 380-500 нм. Авторы показали [123], что интенсивность люминесценции разбавленных растворов неионизованных люминесцентно меченых сополимеров МАГ-МАК и МАГ-АК $(\mathrm{pH}<3)$ практически не изменяется при увеличении концентрации ионов переходных металлов-тушителей люминесценции $\left(\mathrm{Cu}^{2+}, \mathrm{Ni}^{2+}, \mathrm{Ag}^{+}\right)$до $10^{-2}$ моль/л. Но если карбоксильные группы в сополимере ионизованы, то даже при концентрации ионов переходных металлов в растворе $10^{-4}-10^{-6}$ моль/л интенсивность люминесценции резко уменьшается. Это означает, что центрами связывания ионов переходных металлов являются заряженные карбоксильные группы сополимера.

Преимущество данного подхода перед потенциометрическим титрованием заключается в возможности проводить исследования в 
условиях полной ионизации карбоксильных групп и при аномально низких концентрациях полимера и ионов металла. Оказалось, что константы устойчивости подобных комплексов существенно зависят от заряда иона переходного металла, состава сополимера, ионной силы раствора. Тем не менее эти величины слабо меняются при вариации природы вводимого низкомолекулярного электролита, например, $\mathrm{NaCl}$, и химического строения карбоксилсодержащих звеньев. Перечисленные существенные обстоятельства можно использовать для эффективного контроля за состоянием указанных комплексов при их биологическом функционировании в качестве эффективных средств доставки лекарственных средств. Эти факторы также играют важную роль на начальных этапах синтеза наночастиц и нанокластеров металлов, стабилизированных полиэлектролитами.

\section{Метод флуоресиентной коррелящионной спектроскопии}

Флуоресцентная корреляционная спектроскопия (ФКС) основана на измерении флуктуаций флуоресценции отдельных частиц или молекул, возникающих в результате броуновского движения в засвечиваемом лазером объеме раствора (конфокальный объем) [124]. По аналогии с методом ДРС временная зависимость флуктуаций флуоресценции в ФКС описывается автокорреляционной функцией, анализ которой позволяет получить информацию о времени диффузии частиц и их количестве в 
конфокальном объеме. Достоинствами метода ФКС являются (1) использование малого объема исследуемого образца; (2) незначительные концентрации красителя необходимые для анализа, что практически не влияет на исследуемую систему; (3) возможность проведения измерений in situ; (4) высокое пространственное разрешение метода в пределах дифракционных ограничений; (5) возможность наблюдения за диффузией разных объектов одновременно [125].

ФКС может использоваться при исследовании процессов, сопровождающихся изменением подвижности молекул или частиц, например, агрегации коллоидных систем, взаимодействия флуоресцирующих молекул с полимерами [124, 125]. Этот метод является весьма перспективным для исследования полимерных комплексов.

В работе Chehreghanianzabi и Zustiak [126] использован метод ФКС для исследования взаимодействий нескольких водорастворимых полимеров (полиэтиленгликоля, поливинилового спирта, альгината натрия, декстрана и сополимера сахарозы с эпихлоргидрином (Ficoll@ 400) с флуоресцентным красителем Atto655 в водных растворах. Установлено, что молекулы Atto655 теряют свою диффузионную способность в присутствии полимеров и это зависит от химической природы макромолекул и их концентрации в растворе. Так, приблизительно $20 \%$-ое уменьшение диффузионной способности Atto655 наблюдается в присутствии 0.1 вес./об. \% ПЭГ; для альгината натрия и поливинилового спирта такое 
снижение наблюдается лишь при $\geq 0.5$ вес./об. \% и $\geq 1.0$ вес./об.\%, соответственно. Такого существенного снижения диффузионной способности Atto655 не наблюдалось в присутствии декстрана и Ficoll® 400 в том же интервале концентраций полимеров. Анализ полученных данных позволил авторам предположить наличие специфических взаимодействий флуоресцентного красителя с ПЭГ, в случае которого снижение диффузионной способности Atto655 не могло быть связано лишь со снижением свободного объема при увеличении концентрации полимера в pacтворе. При дальнейшем исследовании влияния добавок $\mathrm{NaCl}$ и изменения $\mathrm{pH}$ раствора на характер взаимодействия Atto655 с ПЭГ установлено отсутствие зависимости диффузионной способности красителя от концентрации добавленной соли. В растворах с низкими и высокими значениями $\mathrm{pH}$ (2 и 12, соответственно) специфических взаимодействий красителя с ПЭГ, которые были при $\mathrm{pH} 7.4$, не наблюдается. В присутствии 1 \% добавленного диметилсульфоксида характер взаимодействия Atto655 с ПЭГ существенно меняется: 20 \%-ое снижение диффузионной способности красителя уже не наблюдается в 0.1 вес./об. \% растворе полимера при рН 7.4. На основании полученных данных авторы пришли к выводу, что природой взаимодействия Atto655 с ПЭГ является образование водородных связей между карбоксильными группами красителя и простыми эфирными группами ПЭГ. 


\section{3. Методы исследования энергии межмакромолекулярных взаимодействий}

\section{1. Изотермическое калориметрическое титрование}

Согласно термодинамическим критериям, формирование полимерных комплексов наблюдается в случае, если энергия Гиббса при смешении компонентов $\left(\Delta G_{\text {смеш }}\right)$ в растворах имеет отрицательные значения:

$$
\Delta G_{\text {смеш }}=\Delta H_{\text {смеш }}-T \Delta S_{\text {смеш }},
$$

где $\Delta H_{\text {смеш }}$ и $\Delta S_{\text {смеш }}$ - общая теплота (энтальпия) и общая энтропия процесса смешения компонентов комплекса, соответственно, в растворе при температуре $\mathrm{T}$.

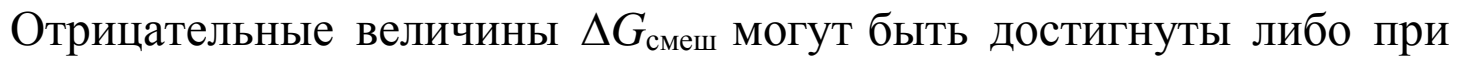



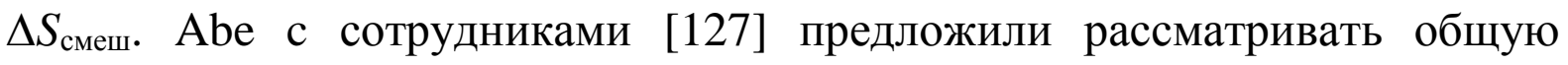
энтальпию смешения $\Delta H_{\text {смеш }}$ для полимер-полимерных комплексов как сумму следующих составляющих:

$$
\Delta H_{\text {смеш }}=\Delta H_{1}+\Delta H_{2}+\Delta H_{3},
$$

где $\Delta H_{1}$ - теплота десольватации, $\Delta H_{2}$ - теплота образования водородных связей и $\Delta H_{3}-$ теплота конформационных изменений макромолекул.

Исследованию термодинамики процессов комплексообразования полимеров посвящены всего несколько ранних работ, в которых в основном применялся метод потенциометрического титрования [128-130]. Этот метод 
отличается простотой и не требует дорогостоящего калориметрического оборудования, однако, имеется ограничение в исследовании комплексообразования для растворов с фиксированными значениями $\mathrm{pH}$. Прямые калориметрические измерения процессов комплексообразования проводились лишь в нескольких ранних работах [131, 132].

Метод изотермического калориметрического титрования (ИКТ) основан на прямых измерениях тепловых эффектов, происходящих при смешении компонентов, взаимодействующих в растворах. Этот метод получил широкое распространение при исследовании биополимеров и их взаимодействия с низкомолекулярными соединениями [133, 134].

Нами был использован метод ИКТ для исследования термодинамики формирования ИПК в растворах ПАК и МЦ [64]. На рис. 12 представлены изотермы для титрования $0.2 \mathrm{вес} \mathrm{\%} \mathrm{водного} \mathrm{раствора} \mathrm{МЦ} \mathrm{раствором} \mathrm{ПАК}$ (2 вес \%) при различных $\mathrm{pH}$. Добавление каждой новой порции раствора ПАК к МЦ сопровождается тепловым эффектом, который записывается в виде пика на термограмме. Обработка таких термограмм позволяет рассчитать стехиометрию образующихся комплексов, энтальпию процесса и константу связывания полимеров в ИПК. 




(a)

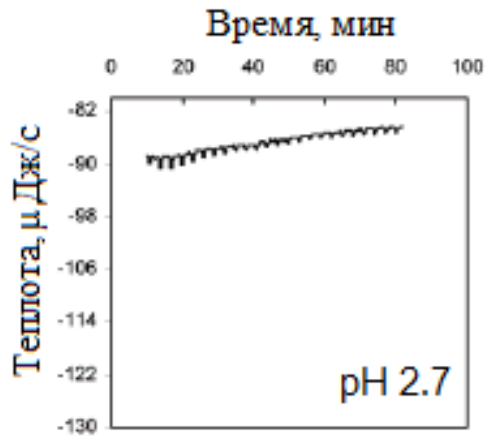

(B)

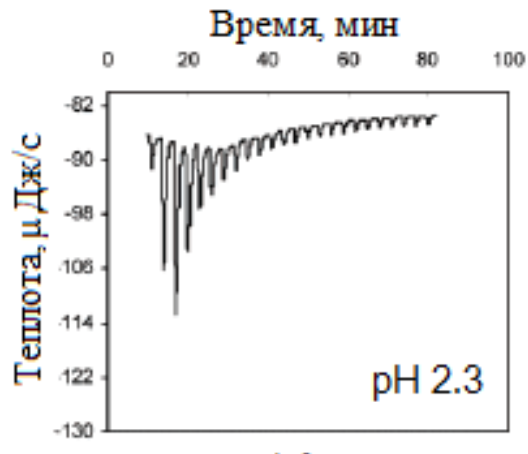

(б)

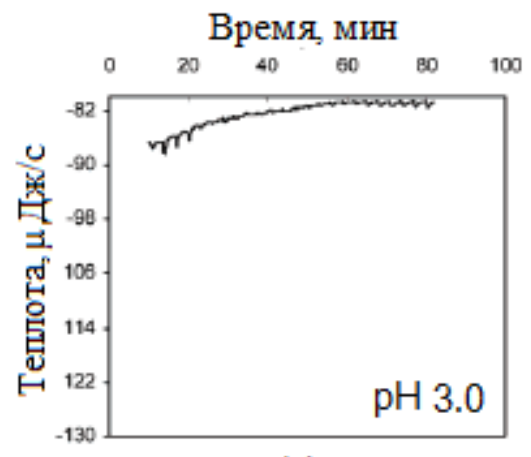

$(\mathrm{r})$

Рис. 12. Термограммы ИКТ титрования 0.2 вес \% водного раствора МЦ раствором 2 вес \% ПАК при рН 2.0 (а), 2.3 (б), 2.7 (в), 3.0 (г). Из работы [64] с разрешения издательства American Chemical Society.

В работе [135] методом ИКТ исследован ряд полимерных систем, образующих ИПК посредством водородных связей. Установлены основные характеристики таких ИПК: константы связывания полимеров в комплекс $K$, стехиометрия ИПК - $n$, а также величины энтальпии комплексообразования $-\Delta H$ (таблица). Анализ данных показал, что несмотря на широкие возможности использования ИКТ для исследования комплексообразования полимеров, этот метод имеет свои ограничения, например, в области чувствительности существующего оборудования к малым изменениям теплоты реакций. 
Таблица. Стехиометрические соотношения, $n$, константы связывания, $K$, и энтальпия образования комплексов, $\Delta H$, с водородными связями. Данные из работы [135]; использованы с разрешения Royal Society of Chemistry.

\begin{tabular}{lcccc}
\hline \multicolumn{1}{c|}{$\begin{array}{c}\text { Комбинация } \\
\text { полимеров }\end{array}$} & $n$ & $K$, моль $^{-1}\left(\times 10^{3}\right)$ & $\begin{array}{c}\Delta H, \\
\text { кДж/моль }\end{array}$ \\
\hline ПАК - декстран & 0 & 0 & 0 \\
ПМАК-декстран & 0 & 0 & 0 \\
Таннин - декстран & 0 & 0 & 0 \\
ПАК - ГЭЦ & 0 & 0 & $0.03 \pm 0.02$ \\
ПМАК - ГЭЦ & 4.25 & $0.550 \pm 0.045$ & $0.17 \pm 0.07$ \\
Таннин - ГЭЦ & 0.27 & $8.260 \pm 0.871$ & $-3.25 \pm 0.21$ \\
ПАК - ПВС & 0.59 & $0.125 \pm 0.010$ & $0.03 \pm 0.01$ \\
ПМАК - ПВС & 0.53 & $7.080 \pm 0.246$ & $0.15 \pm 0.03$ \\
Таннин - ПВС & 0.062 & $6.010 \pm 0.194$ & $2.21 \pm 0.25$ \\
ПАК - МЦ & 1.32 & $2.300 \pm 0.167$ & $0.64 \pm 0.04$ \\
ПМАА - МЦ & 1.40 & $2.090 \pm 0.211$ & $0.51 \pm 0.06$ \\
Таннин - МЦ & 0.06 & $11.500 \pm 0.432$ & $2.25 \pm 0.27$ \\
ПАК - ПЭО & 0.67 & $3.370 \pm 0.312$ & $0.57 \pm 0.04$ \\
ПМАК & 0.68 & $4.430 \pm 0.341$ & $0.67 \pm 0.07$ \\
Таннин - ПЭО & 0.03 & $3.370 \pm 0.312$ & $0.57 \pm 0.04$ \\
ПАК - ПВП & 0.42 & $3.650 \pm 0.213$ & $0.31 \pm 0.06$ \\
ПМАК - ПВП & 1.01 & $3.030 \pm 0.412$ & $0.35 \pm 0.07$ \\
Таннин - ПВП & 0.001 & $2.240 \pm 0.116$ & $-0.67 \pm 0.10$ \\
ПАК - ПААМ & 0.57 & $7.900 \pm 0.854$ & $-1.20 \pm 0.07$ \\
ПМАК - ПААМ & 0.67 & $3.740 \pm 0.351$ & $-1.06 \pm 0.09$ \\
Таннин - ПААМ & 0.06 & $22.100 \pm 3.214$ & $-8.25 \pm 0.99$ \\
ПАК - ПМВЭ & 1.44 & $12.500 \pm 1.983$ & $1.54 \pm 0.32$ \\
ПМАК - ПВМЭ & 1.49 & $10.100 \pm 0.974$ & $1.92 \pm 0.26$ \\
Таннин - ПВМЭ & 0.07 & $206.000 \pm 9.742$ & $12.44 \pm 0.67$ \\
\hline
\end{tabular}

Так, например, при исследовании влияния $\mathrm{pH}$ среды на комплексообразование МЦ и ПАК нами установлено формирование ИПК в широком диапазоне $\mathrm{pH}(2.3$ - 3.0), которое сопровождается повышением мутности раствора [64]. В то же время при исследовании 
комплексообразования методом ИКТ существенные термические эффекты регистрируются только при рН 2.0 и 2.3.

Vitorazi c соавторами [136] исследовано комплексообразование поли(N,N'-диаллил-N,N'-диметиламмоний $\quad$ хлорида) (ПДМАХ) полиакрилатом натрия - ПА(Na) - методами ИКТ, статического и динамического светорассеяния и электрофореза. Установлено, что образование ИПЭК протекает как двустадийный процесс: сначала образуются сильнозаряженные ИПЭК размером 130-140 нм, в которых в избытке присутствует один из полимерных компонентов (в зависимости от порядка смешения растворов полимеров). При дальнейшем добавлении одного из полимеров достигается стехиометрия зарядов, и ИПЭК преобразуются в коацерватные капли, размеры которых составляют несколько микрометров. Методом ИКТ установлено, что первичный процесс комплексообразования характеризуется сравнительно малыми положительными значениями $\Delta H(+4,6 \ldots+5,0$ кДж/моль при добавлении ПДМАХ в раствор ПА(Na) и высокими положительными значениями энтропии $\Delta \mathrm{S} \quad(+82,8 \ldots+87,5$ Дж/моль $\cdot К)$. Эти значения $\Delta \mathrm{S}$ вероятно обусловлены высвобождением противоионов в результате комплексообразования. Данные электрофореза позволили рассчитать электрофоретическую подвижность полимеров и их комплексов и оценить значения ל-потенциала частиц. Установлено, что первичные частицы ИПЭК характеризовались более высокими значениями ל-потенциала: 
- 43 мВ при добавлении ПДМАХ в раствор ПА(Na) и + 53 мВ при обратном титровании. Однако, в момент перехода первичных частиц в коацерваты, эти значения составили -22 мВ и +16 мВ, соответственно. Таким образом электрофоретические исследования комплексообразования дают сведения о заряде и коллоидной стабильности частиц ИПЭК, которые прекрасно дополняют результаты полученные методом ИКТ.

$\mathrm{Fu}$ и Schlenoff [137] методом ИКТ исследовали комплексообразование ПДМАХ с полистиролсульфонатом (ПСС) в присутствии неорганических солей различной природы. Было установлено, что движущей силой комплексообразования полиэлектролитов в присутствии 0.1-2.0 M NaCl на 90-100 \% являются электростатические взаимодействия. Показано, что природа неорганических солей, присутствующих в растворах полиэлектролитов, оказывает определенное влияние на термодинамические параметры комплексообразования. Этот эффект авторы связывают с различным воздействием низкомолекулярных ионов на структуру воды.

Богомоловой с соавторами [138] методами ИКТ, динамического светорассеяния, измерениями электрофоретической подвижности, малоугловым рассеянием нейтронов и инфракрасной спектроскопией исследовано поведение поли(N-метакрилоил-L-валина) (ПМВ), поли(Nметакрилоил-L-аланина) (ПМА) и поли(N-метакрилоилглицина-Lлейцина) (ПМГЛ) в присутствии неионного поверхностно-активного 
вещества (ПАВ) Brij98 в водных растворах с различным рН. Исследование взаимодействий данных полимеров с Brij98 методом ИКТ показало, что связывание ПМА и ПМГЛ с ПАВ имеет экзотермическую природу, в то время как в случае с ПМВ наблюдаются эндотермические эффекты. Авторы связывают такие различия в термодинамике $\mathrm{c}$ разной природой взаимодействий: ПМВ ассоциирует с Brij98 посредством гидрофобных эффектов, ПМА - преимущественно за счет водородных связей, а в случае с ПМГЛ имеет место оба типа взаимодействий. Богомоловой с соавторами [139] также использован метод ИТК в комбинации с другими физикохимическими методами для исследования взаимодействий неионных дифильных триблок-сополимеров на основе поли(2-алкил-2-оксазолинов) с ионными ПАВ - додецилсульфатом натрия и гексадецилтриметиламмоний бромидом при разных температурах. Показано наличие сильных неспецифических взаимодействий блок-сополимера с анионным ПАВ и слабых взаимодействий с катионным ПАВ.

Таким образом, анализ приведенных выше примеров по использованию ИТК в исследовании комплексообразования полимеров в растворах позволяет отметить высокую информативность данного метода в определении природы взаимодействий, стехиометрии комплексов и эффективности связывания. 


\section{2. Метод поверхностного плазмонного резонанса}

Явление поверхностного плазмонного резонанса (ППР) заключается в коллективной осцилляции электронов на поверхности некоторых металлов (обычно, золота или серебра) при их облучении светом с определенной длиной волны. Так, при адсорбции на поверхности золота различных веществ, например, полимеров или биополимеров, характер сигнала ППР меняется, что позволяет исследовать специфические взаимодействия между химическими соединениями. Данный подход получил коммерческое развитие в разработке приборов ППР компанией Biacore (Швеция) и в литературе часто именуется как метод Biacore. Устройства Biacore позволяют проводить быстрые и автоматизированные измерения при пропускании различных растворов через поверхность золотого микросенсора, покрытого определенными функциональными группами [140]. На рис. 13 в качестве примера приведены кривые изменения сигнала ППР на установке Biacore при введении раствора ПАК, с последующим смывом водой (рН 2.0) неадсорбированных макромолекул и дальнейшим введением раствора МЦ [141]. Общий рост интенсивности сигнала ППР указывает на формирование комплекса ПАК-МЦ на поверхности сенсора. 


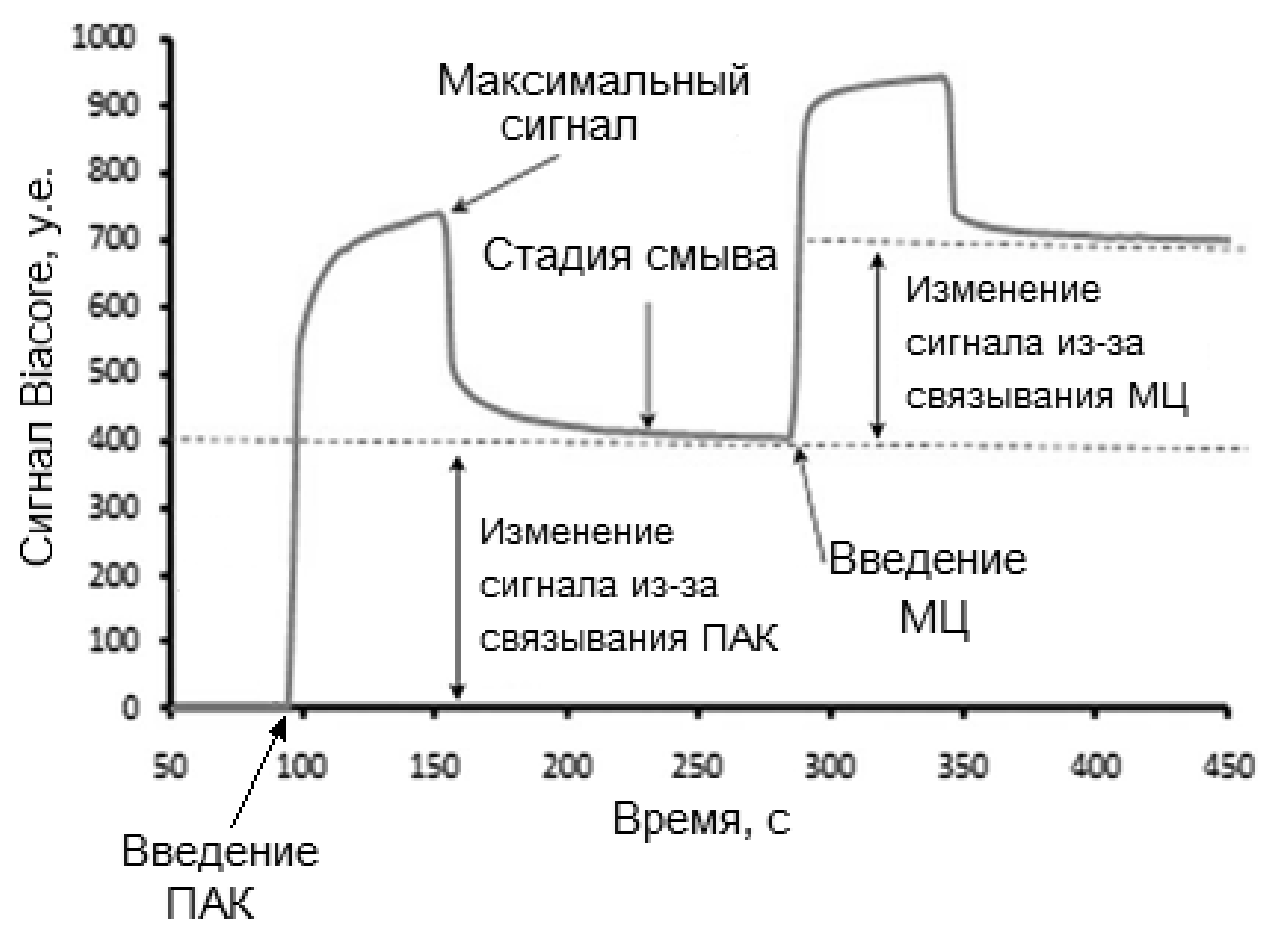

Рис. 13. Кривая сигнала ППР на установке Biacore при связывании 0.2 вес \% ПАК поверхностью сенсора СМ5 (золотой микросенсор, функционализованный карбоксиметилдекстраном) с последующим смывом кислым раствором (pH 2.0) и введением 0.2 вес \% МЦ при $\mathrm{pH} 2.0$. Из работы [141] с разрешения издательства Royal Society of Chemistry.

Применение метода ППР позволяет исследовать формирование полимерных комплексов в реальном времени и оптимизировать условия их получения. Особенно перспективным представляется использование этого метода при оптимизации условий получения полимерных мультислоев методом послойного нанесения (layer-by-layer). В работе [141] применен метод ППР для исследования формирования мультислоев на основе ПАКМЦ и установлены оптимальные значения рН для получения многослойных мембран из таких комплексов. На рис. 14 представлены кривые ППР, записанные при поочередном введении растворов ПАК, воды и МЦ, что 
приводит к образованию мультислоев на поверхности сенсора. В эксперименте при рН 2.0 и 2.5 наблюдают ступенчатую сенсор-грамму, которая характерна для формирования стабильных мультислоев; при рН 3.0 рост сигнала ППР незначителен, что свидетельствует о малой стабильности ИПК. При рН 4.0 сигнал ППР практически не регистрируется, что указывает на отсутствие интерполимерной реакции.

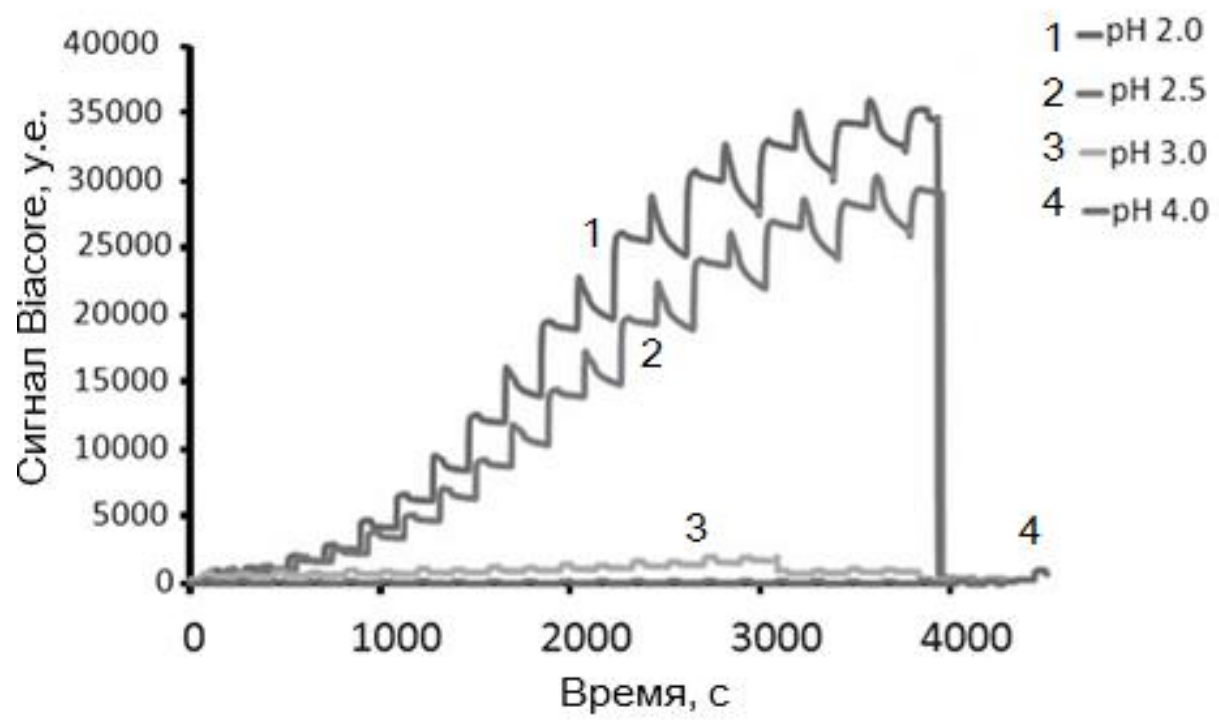

Рис. 14. Кривые сигнала ППР на установке Biacore, записанные при формировании мультислоев ПАК/МЦ при различных $\mathrm{pH}$. Концентрации ПАК и МЦ в растворах 0.2 вес $\%$. Из работы [141] с разрешения издательства Royal Society of Chemistry.

В работе [142] использован метод ППР для исследования формирования мультислоев на основе полиэлектролитных комплексов альгината натрия и хитозана. Установлена возможность применения данного метода не только для подтверждения и оптимизации формирования 
мультислоев, но также и для оценки стабильности образующихся комплексов, например, при изменении рН среды.

\section{4. Аналитическая скоростная седиментация}

Метод аналитического ультрацентрифугирования (или аналитическая скоростная седиментация), основан на различной способности макромолекул или коллоидных частиц, отличающихся по молекулярной массе или размерам и плотности, к седиментации в центробежном поле. Данный метод является абсолютным для определения молекулярных масс полимеров, их молекулярно-массовых распределений, а также характеристик коллоидных частиц. С помощью аналитического ультрацентрифугирования можно также характеризовать различные взаимодействия между макромолекулами разной химической природы [143]. Есть два существенно различающихся подхода, которые можно выполнить с помощью аналитического ультрацентрифугирования.

1. Скоростная седиментация: эксперимент, выполняют на достаточно высокой скорости с целью центрифугировать растворенное или диспергированное вещество вдали от центра вращения на основе слежения за седиментирующей границей. Для данной скорости ротора, вязкости растворителя и его плотности скорость движения границы зависит от размера и формы макромолекул или продукта взаимодействий полимеров в растворах. 
2. Приближение к седиментационному равновесию: эксперимент выполняют на более низкой скорости так, чтобы седиментация и сила обратной диффузии имели сопоставимые величины, из-за чего и возникает равновесное распределение концентрации раствора. Поскольку в равновесном состоянии нет настоящего транспорта вещества, влияние формы макромолекул не играет роли, и распределение становится абсолютной функцией молекулярной массы для отдельного растворенного вещества. Для взаимодействующей системы распределение растворённых компонент есть абсолютное отражение закона действующих масс между соединениями, участвующими в реакции химического равновесия (концентрации, а также молекулярные массы участвующих соединений).

Скоростная седиментация, не обеспечивая абсолютного определения молекулярной массы, может, тем не менее, быть с большим успехом использована для идентификации и характеристики взаимодействий между растворёнными веществами, включая биологические макромолекулы белки с лигандами, а также различные интерполимерные комплексы [144]. В таких исследованиях нужно иметь в виду влияние формы на коэффициенты седиментации предполагаемых комплексов между растворенными веществами. Причём такие допущения становятся не столь и необоснованными, если во взаимодействии участвуют макромолекулы белков с маленькими лигандами (ММ <500). По результатам исследования 
концентрационных зависимостей коэффициента седиментации макромолекул была оценена ММ растворимых производных хитина [145]. Таким образом, в биохимических исследованиях методами скоростной седиментации и приближения к седиментационному равновесию изучают макромолекулярные взаимодействующие системы [146]. Аналитическая скоростная седиментация может быть использована наряду с другими гидродинамическими методами для исследования конформационных состояний линейных макромолекул синтетического и природного происхождения [147-149], либо макромолекул сложной архитектуры (щёток) [150]. Комбинация двух упомянутых выше подходов с использованием ультрацентрифуги может часто прояснить проблему взаимодействий между макромолекулярными и низкомолекулярными компонентами в поликомплексах как биологической, так и синтетической природы [151]. Например, в работе Gelissen с соавторами [152] аналитическое ультрацентрифугирование использовалось для исследования послойного нанесения противоположно-заряженных полиэлектролитов (поли-4-стиролсульфонат натрия и полидиаллилдиметиламмоний хлорид) на поверхность катионных микрогелей на основе сополимеров $\mathrm{N}$-изопропилакриламида $\quad$ и $\quad$ метакриламидопропилтриметиламмоний хлорида. Авторами установлено, что слой поли-4стиролсульфонат натрия, нанесенный на микрогель, прочно удерживается на его поверхности и не отделяется при погружении таких частиц в раствор 
полидиаллилдиметиламмоний хлорида. Эти результаты также подтверждаются данными по электрофоретической подвижности микрогелей.

\section{Заключение}

Современные физико-химические методы анализа, используемые при исследовании комплексообразования полимеров, позволяют существенным образом расширить наши знания об их формировании, структуре и свойствах. Прогресс в этой области в последние годы связан не только с исследованием параметров комплексообразования с применением современных методов анализа, но и с получением новых полимерных систем, имеющих сложную архитектуру, например, комплексы, образованные привитыми и блок-сополимерами, дендримерами, и биологическими полимерами.

В последние годы опубликован ряд работ по определению термодинамических параметров в полимерных системах, установлены структурные особенности комплексов, образованных полимерами сложной архитектурной организации. Получены новые данные по динамике интерполимерных комплексов в растворе. 


\section{Благодарности}

Авторы благодарят заведующего лабораторией ИВС РАН д.ф.-м.н.

Паутова В.Д. и старшего научного сотрудника к.х.н. Некрасову Т.Д. за плодотворную дискуссию при написании обзора.

\section{Литература}

[1] Tsuchida E., Abe K. // Adv Polym Sci 1982. 45. 1-119.

[2] Зезин А.Б., Кабанов В.А. // Успехи Химии 1982. LI. 1447-1483.

[3] Кабанов В.А. // Успехи химии 2005. 74. 5-23.

[4] Philipp B., Dautzenberg H., Linow K.J., Kotz J., Dawydoff W. // Prog Polym Sci 1989. 14. 91-172.

[5] Pergushov D.V., Borisov O.V., Zezin A.B., Müller A.H.E. // Self Organized Nanostructures of Amphiphilic Block Copolymers I 2011. 241. 131-161.

[6] Изумрудов В.А. // Успехи химии 2008. 77. 401-415.

[7] Кабанов А.В., Кабанов В.А. // Высокомолек. соед. А. 1994. 36. 198-211.

[8] Moustafine R.I., Salachova A.R., Frolova E.S., Kemenova V.A., Van den Mooter G. // Drug Dev Ind Pharm 2009. 35. 1439-1451.

[9] Moustafine R.I., Sitenkov A.Y., Bukhovets A.V., Nasibullin S.F., Appeltans B., Kabanova T.V., Khutoryanskiy V.V., Van den Mooter G. // Int J Pharmaceut 2017. 524. 121-133.

[10] Dalmoro A., Sitenkov A.Y., Lamberti G., Barba A.A., Moustafine R.I. // J Appl Polym Sci 2016. 133.

[11] De Geest B.G., Sukhorukov G.B., Mohwald H. // Expert Opin Drug Del 2009. 6. $613-624$.

[12] Кабанов В.А., Паписов И.М. // Высокомолек. соед. А. 1979. 21. 243.

[13] Bekturov E.A., Bimendina L.A. // Adv Polym Sci 1981. 41. 99-147. 
[14] Khutoryanskiy V.V., Staikos G., Hydrogen-bonded interpolymer complexes : formation, structure and applications, World Scientific, Hackensack, NJ ; Singapore, 2009.

[15] Khutoryanskiy V.V. // Int J Pharmaceut 2007. 334. 15-26.

[16] Spevacek J., Schneider B. // Adv Colloid Interfac 1987. 27. 81-150.

[17] Ануфриева Е.В., Краковяк М.Г., Некрасова Т.Н., Смыслов Р.Ю., Лушик В.Б. // ЖПХ 1996. 69. 999 - 1003.

[18] Ануфриева Е.В., Краковяк М.Г., Некрасова Т.Н., Смисллов Р.Ю. // Высокомолек. соед. А. 1996. 38. 310 - 314.

[19] Sun L., Pitto-Barry A., Kirby N., Schiller T.L., Sanchez A.M., Dyson M.A., Sloan J., Wilson N.R., O'Reilly R.K., Dove A.P. // Nat Commun 2014. 5.

[20] Pilate F., Toncheva A., Dubois P., Raquez J.M. // Eur Polym J 2016. 80. 268294.

[21] Tam K.C., Wyn-Jones E. // Chem Soc Rev 2006. 35. 693-709.

[22] Мусабеков К.Б., Жубанов Б.А., Измайлова В.Н., Сумм Б.Д., Межфазные слои полиэлектролитов : (Синтет. полимеры) Наука, Алма-Ата, 1987.

[23] Efimova A.A., Sybachin A.V., Chvalun S.N., Kulebyakina A.I., Kozlova E.V., Yaroslavov A.A. // Polym Sci Ser B+ 2015. 57. 140-144.

[24] Tsuchida E., Nishide H. // Adv Polym Sci 1977. 24. 1.

[25] Бектуров Е.А., Бимендина Л.А., Кудайбергенов С.Е., Полимерные комплексы и катализаторы, Наука, Алма-Ата, 1982.

[26] Khutoryanskiy V.V., Kujawa P., Nurkeeva Z.S., Rosiak J.M. // Macromol Chem Physic 2001. 202. 1089-1093.

[27] Помогайло А.Д., Полимерные иммобилизованные металлокомплексные катализаторы, Наука, М., 1988.

[28] Aal A.S.A., Khutoryanskiy V.V., Nurkeeva Z.S., Mun G.A. // J Mater Chem 2002. 12. 2692-2695.

[29] Grishin I.D., Kiseleva N.E., Markin A.V., Chizhevsky I.T., Grishin D.F. // Polym Sci Ser B+ 2015. 57. 1-8. 
[30] Smyslov R.Y., Ezdakova K.V., Kopitsa G.P., Khripunov A.K., Bugrov A.N., Tkachenko A.A., Angelov B., Pipich V., Szekely N.K., Baranchikov A.E., Latysheva E., Chetverikov Y.O., Haramus V. // J. Phys.: Conf. Ser. 2017. 848. 012017.

[31] Velichko E.V., Buyanov A.L., Saprykina N.N., Chetverikov Y.O., Duif C.P., Bouwman W.G., Smyslov R.Y. // Eur Polym J 2017. 88. 269-279.

[32] Bunzli J.C.G. // Coordin Chem Rev 2015. 293. 19-47.

[33] Якиманский А.В., Краковяк М.Г., Гойхман М.Я., Смыслов Р.Ю., Подешво И.В., Лореиян Н.Л., Некрасова Т.Н., Ананьева Т.Д., Ануфриева Е.В. // Высокомолек. соед. А. 2010. 52. 32-37.

[34] Якиманский А.В., Гойхман М.Я., Подешво И.В., Ананьева Т.Д., Некрасова Т.Н., Смыслов Р.Ю. // Высокомолекулярные соединения, Серия А 2012. 54. 1699-1721.

[35] Smirnov V.A., Philippova O.E., Sukhadolski G.A., Khokhlov A.R. // Macromolecules 1998. 31. 1162-1167.

[36] Nurkeeva Z.S., Mun G.A., Khutoryanskiy V.V., Bitekenova A.B., Dzhusupbekova A.B. // J Biomat Sci-Polym E 2002. 13. 759-768.

[37] Nurkeeva Z.S., Khutoryanskiy V.V., Mun G.A., Sherbakova M.V., Ivaschenko A.T., Aitkhozhina N.A. // Eur J Pharm Biopharm 2004. 57. 245-249.

[38] Oliva M., Diez-Perez I., Gorostiza P., Lastra C.F., Oliva I., Caramella C., Marino E.L. // J Pharm Sci 2003. 92. 77-83.

[39] Gombotz W.R., Wee S.F. // Adv Drug Deliver Rev 1998. 31. 267-285.

[40] Cook M.T., Tzortzis G., Charalampopoulos D., Khutoryanskiy V.V. // J Control Release 2012. 162. 56-67.

[41] Pergushov D.V., Zezin A.A., Zezin A.B., Müller A.H.E. // Polyelectrolyte Complexes in the Dispersed and Solid State I: Principles and Theory 2014. 255. 173-225.

[42] Chen Y., Pang Y., Wu J.L., Su Y., Liu J.Y., Wang R.B., Zhu B.S., Yao Y.F., Yan D.Y., Zhu X.Y., Chen Q. // Langmuir 2010. 26. 9011-9016.

[43] Бектуров Е.А., Легкунеи Р.Е., Ассочиачия полимеров с малыми молекулами, Наука, Алма-Ата, 1983.

[44] Зезин А.Б., Рогачёва В.Б., Полиэлектролитные комплексы, in: Успехи 
химии и физики полимеров, М., 1973, рр. 3-30.

[45] Бектуров Е.А., Бимендина Л.А., Интерполимерные комплексы, Наука, Алма-Ата:, 1977.

[46] Эскин В.Е., Рассеяние света растворами полимеров и свойства макромолекул, Наука, Л., 1986.

[47] Эскин B.E. // Успехи Физических Наук 1964. 82. 649-706.

[48] - D.H.I., http://www.wyatt.com/products/instruments/dawn-heleos-ii-multiangle-light-scattering-detector.html.

[49] Zimm B.H. // J. Chem. Phys. 1948. 16. 1093

[50] Yudin I.K., Nikolaenko G.L., Kosov V.I., Agayan V.A., Anisimov M.A., Sengers J.V. // Int J Thermophys 1997. 18. 1237-1248.

[51] Frisken B.J. // Appl Optics 2001. 40. 4087-4091.

[52] Berne B.J., Pecora R., Dynamic light scattering : with applications to chemistry, biology, and physics, Dover ed., Dover Publications, Mineola, N.Y., 2000 .

[53] Block I.D., Scheffold F. // Rev Sci Instrum 2010. 81.

[54] Litmanovich E.A., Zakharchenko S.O., Stoychev G.V., Zezin A.B. // Polymer Science A 2009. 51. 616-621.

[55] Ioan C.E., Aberle T., Burchard W. // Macromolecules 1999. 32. 7444-7453.

[56] Zhunuspayev D.E., Mun G.A., Hole P., Khutoryanskiy V.V. // Langmuir 2008. 24. 13742-13747.

[57] Pergushov D.V., Babin I.A., Plamper F.A., Zezin A.B., Müller A.H. // Langmuir 2008. 24. 6414-6419.

[58] Usaitis A., Maunu S.L., Tenhu H. // Eur Polym J 1997. 33. 219-223.

[59] www.nanosight.com

[60] Carr B., Wright M., Nanoparticle Tracking Analysis. A review of applications and usage 2010-2012, NanoSight Ltd, 2013.

[61] Mun E.A., Hannell C., Rogers S.E., Hole P., Williams A.C., Khutoryanskiy V.V. 
// Langmuir 2014. 30. 308-317.

[62] SwansonVethamuthu M., Dubin P.L., Almgren M., Li Y.J. // J Colloid Interf Sci 1997. 186. 414-419.

[63] Gardlund L., Wagberg L., Norgren M. // J Colloid Interf Sci 2007. 312. 237246.

[64] Khutoryanskaya O.V., Williams A.C., Khutoryanskiy V.V. // Macromolecules 2007. 40. 7707-7713.

[65] Golan S., Talmon Y. // Langmuir 2012. 28. 1668-1672.

[66] Aravindan L., Bicknell K.A., Brooks G., Khutoryanskiy V.V., Williams A.C. // Int J Pharmaceut 2009. 378. 201-210.

[67] Schacher F., Betthausen E., Walther A., Schmalz H., Pergushov D.V., Müller A.H.E. // Acs Nano 2009. 3. 2095-2102.

[68] Потатуркина-Нестерова Н.И., Немова И.С., Даньшина А.В. // Современные проблемы науки и образования 2012. URL: https://www.scienceeducation.ru/ru/article/view?id=6348

[69] Schatzlein A.G., Zinselmeyer B.H., Elouzi A., Dufes C., Chim Y.T.A., Roberts C.J., Davies M.C., Munro A., Gray A.I., Uchegbu I.F. // J Control Release 2005. 101. 247-258.

[70] Xu Y.Y., Borisov O.V., Ballauff M., Müller A.H.E. // Langmuir 2010. 26. 69196926.

[71] Horkay F., Hammouda B. // Colloid Polym Sci 2008. 286. 611-620.

[72] Radulescu A., Pipich V., Frielinghaus H., Appavou M.S. // J Phys Conf Ser 2012. 351 .

[73] Feoktystov A.V., Frielinghaus H., Di Z.Y., Jaksch S., Pipich V., Appavou M.S., Babcock E., Hanslik R., Engels R., Kemmerling G., Kleines H., Ioffe A., Richter D., Bruckel T. // J Appl Crystallogr 2015. 48. 61-70.

[74] Goerigk G., Varga Z. // J Appl Crystallogr 2011. 44. 337-342.

[75] Zaroslov Y.D., Gordeliy V.I., Kuklin A.I., Islamov A.H., Philippova O.E., Khokhlov A.R., Wegner G. // Macromolecules 2002. 35. 4466-4471.

[76] Radulescu A., Kentzinger E., Stellbrink J., Dohmen L., Alefeld B., Rucker U., Heiderich M., Schwahn D., Bruckel T., Richter D. // Neutron News 2005. 16. 18-21. 
[77] Wignall G.D., Bates F.S. // J Appl Crystallogr 1987. 20. 28-40.

[78] QtiKWS, in http://iffwww.iff.kfa-juelich.de/ pipich/dokuwiki/doku.php/qtikws.

[79] Schmatz W., Springer T., Schelten J., Ibel K. // J Appl Crystallogr 1974. 7. 96116.

[80] Hammouda B., Mildner D.F.R. // J Appl Crystallogr 2007. 40. 250-259.

[81] Filippov S.K., Verbraeken B., Konarev P.V., Svergun D.I., Angelov B., Vishnevetskaya N.S., Papadakis C.M., Rogers S., Radulescu A., Courtin T., Martins J.C., Starovoytova L., Hruby M., Stepanek P., Kravchenko V.S., Potemkin I.I., Hoogenboom R. // J Phys Chem Lett 2017. 8. 3800-3804.

[82] Zeghal M., Auvray L. // Europhys Lett 1999. 45. 482-487.

[83] Merta J., Garamus V.M., Kuklin A.I., Willumeit R., Stenius P. // Langmuir 2000. 16. 10061-10068.

[84] Sotiropoulou M., Oberdisse J., Staikos G. // Macromolecules 2006. 39. 30653070 .

[85] Rajapaksha A., Stanley C.B., Todd B.A. // Biophys J 2015. 108. 967-974.

[86] Svergun D.I., Richard S., Koch M.H.J., Sayers Z., Kuprin S., Zaccai G. // P Natl Acad Sci USA 1998. 95. 2267-2272.

[87] Novoskoltseva O.A., Chernikova E.V., Rogacheva V.B., Zezin A.B. // Polym Sci Ser B+ 2015. 57. 132-139.

[88] Izumrudov V.A. // Usp Khim+ 2008. 77. 401-415.

[89] Ануфриева Е.В., Панарин Е.Ф., Паутов В.Д., Семисотнов Г.В., Соловский М.В. // Высокомолек. соед. Сер. А. 1977. 19. 1329.

[90] Anufrieva E.V., Krakovyak M.G., Nekrasova T.N., Smyslov R.Y., in: V.V. Khutoryanskiy, G. Staikos (Eds.) Hydrogen Bonded Interpolymer Complexes: Formation, Structure and Application, World Scientific Pub Co Inc, Singapore, 2009.

[91] Владимиров Ю.А., Добреиов Г.Е., Флуоресиентные зонды в исследовании биологических мембран, Наука, М., 1980.

[92] Khutoryanskiy V.V., Dubolazov A.V., Nurkeeva Z.S., Mun G.A. // Langmuir 2004. 20. 3785-3790. 
[93] Nurkeeva Z.S., Mun G.A., Dubolazov A.V., Khutoryanskiy V.V. // Macromol Biosci 2005. 5. 424-432.

[94] Dubolazov A.V., Nurkeeva Z.S., Mun G.A., Khutoryanskiy V.V. // Biomacromolecules 2006. 7. 1637-1643.

[95] Нуркеева 3.С., Мун Г.А., Хуторянский В.В. // Высокомолек. Соед. Сер. Б. 2001. 43. 925.

[96] Khutoryanskiy V.V., Mun G.A., Nurkeeva Z.S., Dubolazov A.V. // Polym Int 2004. 53. 1382-1387.

[97] Pergushov D.V., Remizova E.V., Feldthusen J., Zezin A.B., Müller A.H.E., Kabanov V.A. // J Phys Chem B 2003. 107. 8093-8096.

[98] Anufrieva E.V., Gotlib Y.Y. // Adv Polym Sci 1981. 40. 1-69.

[99] Бартеньев Г.М., Релаксаџионные явления в полимерах, Химия, Л., 1972.

[100] Готлиб Ю.Я., Даринский А.А., Светлов Ю.Е., Физическая кинетика макромолекул, Химия, Л., 1986.

[101] Григорьев С.Б., Михайлов И.Г., Акустические методы исследования структуры полимеров в растворе, in: Современные физические методы исследования полимеров., Химия, М., 1982, рр. 185-198.

[102] Михайлов И.Г., Сафарина Э.Б., Фёдорова Н.М. // Вестник ЛГУ 1972. 1. 55-61.

[103] Ullman R. // J. Chem. Phys. 1965. 43. 3161-3177.

[104] Феррар Т., Беккер Э., Импульсная и Фурье-спектроскопия ЯМР, Мир, М., 1979.

[105] Рубан А.Б., Современные методы биофизических исследований, Высшая школа, М., 1988.

[106] Liu K.-J., Anderson J.E. // J. Macromol. Sci.- Revs. Macromol. Chem. 1970. 5. 1-28.

[107] Вассерман А.М., Коварский А.Л., Спиновые метки и зонды в фотохимии полимеров, Наука, М., 1986

[108] Михайлов Г.П., Лобанов А.М., Платонов М.П. // Высокомолек. соед. 1966. 8. 692-698. 
[109] Буритейн Л.Л., Малиновская В.П. // Высокомолек. соед. А. 1973. 15. 7379.

[110] Борисова Т.И., Бурштейн Л.Л., Исследование структуры полимеров диэлектрическим методом, іп: Современные методы исследования полимеров, Химия, М., 1982, рр. 155-169.

[111] North A.M. // Chem Soc Rev 1972. 1. 49-\&.

[112] Krutyeva M., Wischnewski A., Monkenbusch M., Willner L., Maiz J., Mijangos C., Arbe A., Colmenero J., Radulescu A., Holderer O., Ohl M., Richter D. // Phys Rev Lett 2013. 110.

[113] Scherzinger C., Holderer O., Richter D., Richtering W. // Phys Chem Chem Phys 2012. 14. 2762-2768.

[114] Martin J., Krutyeva M., Monkenbusch M., Arbe A., Allgaier J., Radulescu A., Falus P., Maiz J., Mijangos C., Colmenero J., Richter D. // Phys Rev Lett 2010. 104.

[115] Gallat F.X., Brogan A.P.S., Fichou Y., McGrath N., Moulin M., Hartlein M., Combet J., Wuttke J., Mann S., Zaccai G., Jackson C.J., Perriman A.W., Weik M. // J Am Chem Soc 2012. 134. 13168-13171.

[116] Ануфриева Е.В., Краковяк М.Г., Некрасова Т.Н., Т.В. Ш. // Высокомолек. соед. Б. 2004. 46. 1954-1958.

[117] Anufrieva E.V., Gromova R.A., Kirsh Y.E., Yanul N.A., Krakovyak M.G., Lushchik V., Pautov V.D., Sheveleva T.V. // Eur Polym J 2001. 37. 323-328.

[118] Некрасова Т.Н., Паутов В.Д., Ананьева Т.Д., Иманбаев Р.Т., Смыслов Р.Ю., Теньковиев А.В. // Высокомолек. соед. А. 2015. 57. 8-14.

[119] Паутов В.Д., Некрасова Т.Н., Ананьева Т.Д., Мелешко Т.К., Ильгач Д.М., Якиманский А.В. // Высокомолек. соед. А. 2013. 55. 1154-1162.

[120] Паутов В.Д., Некрасова Т.Н., Ананьева Т.Д., Мелешко Т.К., Ильгач Д.М., Якиманский А.В. // Высокомолек. соед. А. 2013. 55. 1163-1167.

[121] George B., Pillai V.N.R., Mathew B. // J Macromol Sci Pure 1998. A35. 495510.

[122] Паутов Д.В., Ануфриева Е.В., Ананьева Т.Д., Лушик В.Б., Некрасова Т.Н., Смыслов Р.Ю. // Высокомолекулярные соединения. Серия А 2006. 48. 299-308.

[123] Паутов В.Д., Ананьева Т.Д., Левит М.Л., Назарова О.В., Панарин Е.Ф. // 
Высокомол. соед. 2016. 58. 466-470.

[124] Перевощикова И.В., Котова Е.А., Антоненко Ю.Н. // Биохимия 2011. 76. 613-635.

[125] Woll D. // Rsc Adv 2014. 4. 2447-2465.

[126] Chehreghanianzabi Y., Zustiak S.P. // Macromol Res 2016. 24. 995-1002.

[127] Abe K., Ohno H., Nii A., Tsuchida E. // Makromol Chem 1978. 179. 2043 2050 .

[128] Паписов И.М. // Высокомолек. Соед. Сер. А. 1974. 16. 1133.

[129] Staikos G., Karayanni K., Mylonas Y. // Macromol Chem Physic 1997. 198. 2905-2915.

[130] Tsuchida E., Osada Y., Ohno H. // J Macromol Sci Phys 1980. B17. 683-714.

[131] Барановский В.Ю., Зенков И.Д., Кабанов В.А. // Высокомолек. Соед. Сер. A. 1989. 31. 493.

[132] Eagland D., Crowther N.J., Butler C.J. // Eur Polym J 1994. 30. 767-773.

[133] Freire E. // Drug discovery today. Technologies 2004. 1. 295-299.

[134] Freyer M.W., Lewis E.A. // Methods in cell biology 2008. 84. 79-113.

[135] Bizley S.C., Williams A.C., Khutoryanskiy V.V. // Soft Matter 2014. 10. 82548260 .

[136] Vitorazi L., Ould-Moussa N., Sekar S., Fresnais J., Loh W., Chapel J.P., Berret J.F. // Soft Matter 2014. 10. 9496-9505.

[137] Fu J.C., Schlenoff J.B. // J Am Chem Soc 2016. 138. 980-990.

[138] Bogomolova A., Keller S., Klingler J., Sedlak M., Rak D., Sturcova A., Hruby M., Stepanek P., Filippov S.K. // Langmuir 2014. 30. 11307-11318.

[139] Bogomolova A., Filippov S.K., Starovoytova L., Angelov B., Konarev P., Sedlacek O., Hruby M., Stepanek P. // J Phys Chem B 2014. 118. 4940-4950.

[140] Gopinath S.C.B. // Sensor Actuat B-Chem 2010. 150. 722-733.

[141] Bizley S.C., Williams A.C., Kemp F., Khutoryanskiy V.V. // Soft Matter 2012. 
[142] Cook M.T., Tzortzis G., Khutoryanskiy V.V., Charalampopoulos D. // J Mater Chem B 2013. 1. 52-60.

[143] Harding S.E., Gillis R.B., Adams G.G. // Biophysical reviews 2016. 8. 299308.

[144] Patel T.R., Winzor D.J., Scott D.J. // Methods 2016. 95. 55-61.

[145] Павлов Г.М., С.Г. С. // Высокомолекулярные соединения. Серия А 1986. 28. 1727-1731.

[146] Gohon Y., Pavlov G., Timmins P., Tribet C., Popot J.L., Ebel C. // Anal Biochem 2004. 334. 318-334.

[147] Pavlov G.M., Okatova O.V., Gubarev A.S., Gavrilova I.I., Panarin E.F. // Macromolecules 2014. 47. 2748-2758.

[148] Almutairi F.M., Adams G.G., Kok M.S., Lawson C.J., Gahler R., Wood S., Foster T.J., Rowe A.J., Harding S.E. // Carbohyd Polym 2013. 97. 203-209.

[149] Wang X.Y., Ye X.D., Zhang G.Z. // Nanomed-Nanotechnol 2016. 12. 536-537.

[150] Pavlov G.M., Breul A.M., Hager M.D., Schubert U.S. // Macromol Chem Physic 2012. 213. 904-916.

[151] Pavlov G.M., Harding S.E., Rowe A.J. // Prog Coll Pol Sci S 1999. 113. 7680.

[152] Gelissen A.P.H., Schmid A.J., Plamper F.A., Pergushov D.V., Richtering W. // Polymer 2014. 55. 1991-1999. 